\title{
How essential are Argo observations to constrain a global ocean data assimilation system?
}

\author{
V. Turpin ${ }^{1, a}$, E. Remy ${ }^{1}$, and P. Y. Le Traon ${ }^{1,2}$ \\ ${ }^{1}$ Mercator Ocean, Parc Technologique du Canal, 8-10 rue Hermès, 31520 Ramonville Saint Agne, France \\ ${ }^{2}$ IFREMER, Technopôle Brest Iroise, Z.I de la Pointe du Diable, 29280 Plouzané, France \\ ${ }^{a}$ now at: LOCEAN, Institut Pierre Simon Laplace, 4, place Jussieu 75252 Paris, France \\ Correspondence to: V. Turpin (vtlod@locean-ipsl.upmc.fr)
}

Received: 12 March 2015 - Published in Ocean Sci. Discuss.: 22 June 2015

Revised: 22 October 2015 - Accepted: 6 November 2015 - Published: 16 February 2016

\begin{abstract}
Observing system experiments (OSEs) are carried out over a 1-year period to quantify the impact of Argo observations on the Mercator Ocean $0.25^{\circ}$ global ocean analysis and forecasting system. The reference simulation assimilates sea surface temperature (SST), SSALTO/DUACS (Segment Sol multi-missions dALTimetrie, d'orbitographie et de localisation précise/Data unification and Altimeter combination system) altimeter data and Argo and other in situ observations from the Coriolis data center. Two other simulations are carried out where all Argo and half of the Argo data are withheld. Assimilating Argo observations has a significant impact on analyzed and forecast temperature and salinity fields at different depths. Without Argo data assimilation, large errors occur in analyzed fields as estimated from the differences when compared with in situ observations. For example, in the 0-300 $\mathrm{m}$ layer RMS (root mean square) differences between analyzed fields and observations reach $0.25 \mathrm{psu}$ and $1.25^{\circ} \mathrm{C}$ in the western boundary currents and $0.1 \mathrm{psu}$ and $0.75^{\circ} \mathrm{C}$ in the open ocean. The impact of the Argo data in reducing observation-model forecast differences is also significant from the surface down to a depth of $2000 \mathrm{~m}$. Differences between in situ observations and forecast fields are thus reduced by $20 \%$ in the upper layers and by up to $40 \%$ at a depth of $2000 \mathrm{~m}$ when Argo data are assimilated. At depth, the most impacted regions in the global ocean are the Mediterranean outflow, the Gulf Stream region and the Labrador Sea. A significant degradation can be observed when only half of the data are assimilated. Therefore, Argo observations matter to constrain the model solution, even for an eddy-permitting model configuration. The impact of the Argo floats' data assimilation on other model variables is briefly assessed: the
\end{abstract}

improvement of the fit to Argo profiles do not lead globally to unphysical corrections on the sea surface temperature and sea surface height. The main conclusion is that the performance of the Mercator Ocean $0.25^{\circ}$ global data assimilation system is heavily dependent on the availability of Argo data.

\section{Introduction}

Argo is the first ever in situ ocean observing system providing in real-time observations at global scale. The initial target of 3000 profiling floats drifting in the ocean was reached by the international Argo program in November 2007. Mean coverage is one float in every $3^{\circ} \times 3^{\circ}$ box. Every 10 days, each float measures temperature and salinity profiles from the surface to $2000 \mathrm{~m}$ and delivers data in real time, mostly for operational oceanography. Rigorous scientific quality control is applied by data centers in delayed time to guarantee optimal quality for this data set (e.g., Cabanes et al., 2010; Wong et al., 2008). The use of Argo data is widespread in the ocean and climate research communities. Argo also provides critical observations to constrain ocean analysis and forecasting systems, together with satellite observations.

Operational oceanography capabilities have improved dramatically since the end of the 1990s thanks to the development of real-time in situ and satellite global observing systems (in particular Argo and satellite altimetry) and the improvement of modeling and data assimilation techniques (e.g., Bell et al., 2009). Data assimilation techniques now provide efficient tools for analyzing the impact and improv- 
ing the design of Global Ocean Observing Systems (GOOS) (e.g., Fujii et al., 2014; Lea et al., 2013).

The OceanObs'09 conference held in Venice in September 2009 for the international coordination of interdisciplinary ocean observation highlighted the need to consolidate and improve the design of the global ocean observing system (Lindstrom et al., 2012). To meet this requirement, it is crucial to evaluate and quantify how the existing observation system constrains ocean analysis and forecasting systems. Observing system experiments (OSEs) are a classical tool for evaluating the impact and importance of an observing system on a data assimilation system. OSEs involve the systematic withholding of a subset of observations. The evaluation of the degradation in quality of the resulting analyses and forecasts is then used to quantify the impact of the observations withheld.

In the last decade, several studies based on OSEs have analyzed the impact of different components of the global ocean observing system for ocean analysis and forecasting. Balmaseda et al. (2007) studied the statistical impact of Argo on analyses of the global ocean for the period 20012006. Oke and Schiller (2007) analyzed the importance of the combination of Argo, sea surface temperature (SST) and altimeter data on a regional eddy-resolving ocean reanalysis. Other relevant studies (e.g., Vidard et al., 2007; Tranchant et al., 2008; Guinehut et al., 2012 or more recently Fujii et al., 2014 and Lea et al., 2014) have focused on different observing systems and assessed their impact on analysis and forecasting systems. The GODAE OceanView program (https://www.godae-oceanview.org/), created to promote and coordinate operational oceanography worldwide, has set up a specific OSE task team (OSEval-TT) to formulate requirements for the enhancement of the global ocean observing system (Oke, 2015a, b). The Tropical Pacific Observing System 2020 GOOS project (Global Ocean Observing System; OOPC, 2014) has also identified the importance of OSEs for assessing the role of the Tropical Pacific Observing system from a data assimilation perspective.

In this paper, we focus on the impact of the Argo observing system on the analyzed temperature $(T)$ and salinity $(S)$ structure of the ocean in the context of short-term real-time ocean analysis and forecasts. Several OSEs are performed to assess the importance of Argo $T$ and $S$ profile data assimilation with the real-time Mercator Ocean global $0.25^{\circ}$ system. All other data sets, non-Argo in situ data, SST and alongtrack SLA (sea level anomaly), are assimilated as it is done in the real-time system. The paper is organized as follows: the real-time analysis and forecasting system and the experimental strategy are described in Sect. 2. Section 3 details the results. The differences seen in the analyzed $T$ and $S$ fields depending on the amount of Argo data assimilated are first described. We then evaluate the Argo data assimilation impact on the forecasted fields by looking at the observation forecast misfit to the in situ $T$ and $S$ profiles, SST and SSH (sea surface height). The conclusions are given in Sect. 4.

\section{Tools and methods}

\subsection{Data assimilation system}

The Mercator Ocean $0.25^{\circ}$ operational global ocean analysis and forecasting system (Lellouche et al., 2013) (hereafter referred to as PSY3) was used for this study. The PSY3 system has been operational since 2005 . It routinely assimilates SLA, satellite SST and in situ data. The model is Version 3.1 of NEMO (Nucleus for European Modelling of the Ocean; Madec and the NEMO team, 2008) with a $0.25^{\circ}$ tri-polar ORCA grid. The horizontal resolution is $27 \mathrm{~km}$ at the Equator and decreases to $6 \mathrm{~km}$ toward the poles. A total of 50 vertical levels are used and discretization decreases from $1 \mathrm{~m}$ resolution at the surface down to $450 \mathrm{~m}$ at the bottom, with 22 levels within the upper $100 \mathrm{~m}$. The NEMO system uses the OPA (Océan PArallélisé) ocean model coupled with the LIM2 ice model (Fichefet and Morales Maqueda, 1997). Three-hour atmospheric fields of the European Centre of Medium Weather Forecasting (ECMWF) are used to force the ocean and ice models. Momentum, heat and freshwater fluxes are computed from CORE (Coordinated OceanIce Reference Experiment) bulk formulae (Large and Yeager, 2009). The data assimilation scheme was developed at Mercator Ocean (Tranchant at al., 2008; Lellouche et al., 2013). It is based on a reduced-order (singular evolutive extended) Kalman filter (SEEK) (Pham et al., 1998) with localized 3-D multivariate modal decomposition of the forecast error and a 7-day assimilation window. The background error covariance matrix is static over the assimilation window of 7 days and varies "climatologically" over the year. It is estimated from an ensemble of anomalies computed from a multiyear, forced simulation. The time of the analysis corresponds to the middle of the assimilation window, the fourth day. The increment on temperature and salinity, computed during the analysis step from the in situ profile innovations, is projected onto the barotropic height and $U, V$ fields thanks to the multivariate properties of the model covariance matrix. A 3-Dvariational scheme provides a correction of the slowly evolving large-scale biases in temperature and salinity below the mixed layer. There is no in situ climatology or reference field relaxation in the system. The calculated increments are added to the model solution progressively in time over the assimilation window using an incremental analysis update (IAU) method (Bloom at al., 1996) to avoid spin-up effects at the beginning of each assimilation cycle.

The 2012 assimilated observation data sets are real-time along-track altimeter SLA data from SSALTO/DUACS (Segment Sol multi-missions dALTimetrie, d'orbitographie et de localisation précise/Data unification and Altimeter combination system; Dibarboure et al., 2011). Mean dynamic topography (MDT), used as a reference for SLA data assimilation, is based on the "CNES-CLS09" MDT derived from observations and described in Rio et al. (2011). The assimilated SST observations are the NCDC/NOAA daily high- 
resolution SST analysis at $0.25^{\circ}$ resolution (Reynolds et al., 2007). Real-time in situ temperature and salinity profiles from the Coriolis data center are also assimilated. A subsampling is done before assimilation to keep only one observation per platform per day, within a distance of $0.1^{\circ}$. Only one value is kept on the vertical for each model layer. The observation error variance specified in the assimilation scheme takes into account a representativity error and an instrument error.

\subsection{In situ observations}

The 2012 in situ data set is extracted from the real-time Coriolis database, where automated quality controls are applied. Coriolis is the in situ component of the French operational oceanography infrastructure. It provides real-time and qualified ocean in situ measurements to the European MyOcean project (Copernicus Marine Service) and to research and climate communities. Coriolis collects, controls and standardizes temperature and salinity profiles from different types of instruments including Argo floats, CTDs from research vessels, expendable bathythermographs (XBTs), moorings, sea mammals, gliders and drifting buoys. In term of data number, Argo is currently by far the most important source of information for in situ temperature and salinity profiles.

Argo floats provide measurements of temperature and salinity from the surface to $2000 \mathrm{~m}$ every 10 days at the global scale. The XBT network provides temperature measurements mostly along the main shipping routes from the surface to $800 \mathrm{~m}$. Moorings are mostly in the tropical oceans with TAO/TRITON moorings for the Pacific, PIRATA for the Atlantic and RAMA for the Indian Ocean. Typically, the buoys sample the ocean from the surface down to 500 or $750 \mathrm{~m}$ with $10-15$ levels. Other moorings sample specific regions such as the Drake Passage or the Labrador Sea. CTDs carried by sea mammals are located in high-latitude regions such as the Svalbard Islands, the French Southern and Antarctic Lands, the Ross Sea and Kerguelen region. Gliders are used to sample temperature and salinity from the surface to a given parking depth in specific areas of interest. There is not yet a global measurement strategy for such an observing system.

The 2012 coverage of the in situ data set is shown in Fig. 1. Figure $1 \mathrm{a}$ and $\mathrm{b}$ each correspond to $50 \%$ of the Argo data sets. To ensure that all Argo profiles were selected, we sorted data from the instrument type variable, WMO_INST_TYPE, specified as "VERTICAL PROFILING: observation" for Argo floats in the Coriolis data set. The most realistic way of dividing up the Argo data set and of keeping coherent spatial and temporal resolution was therefore to sort it by platform numbers. Odd-numbered Argo platforms are shown in Fig. 1a, even ones in Fig. 1b. One of the most striking features of these two plots is the global and dense coverage of the oceans. The sparse distribution of the No Argo data set (green dots) is also remarkable. Some regions are rather
Table 1. List of OSEs carried out as part of this study.

\begin{tabular}{lllll}
\hline & SST & $\begin{array}{l}\text { Altimeter } \\
\text { SLA }\end{array}$ & Argo & $\begin{array}{l}\text { Other } \\
\text { in situ }\end{array}$ \\
\hline Run-Ref & yes & yes & $100 \%$ of the array & yes \\
Run-Argo2 & yes & yes & $50 \%$ of the array & yes \\
Run-NoArgo & yes & yes & no & yes \\
Free Run & no & no & no & no \\
\hline
\end{tabular}

more densely sampled by No Argo platforms than others. For example, the Kuroshio and North Atlantic areas are highly sampled compared to the southwest Pacific. Figure 2 represents the time coverage of temperature (Fig. 2a) and salinity (Fig. 2b) profiles from the surface down to $2000 \mathrm{~m}$ for the last 6 months of 2012. The time distribution is fairly regular and no specific feature should impact our conclusions.

\subsection{Experiment design}

The OSEs presented here focus on the impact of the Argo observing system on temperature and salinity analysis and forecasts. Three experiments were performed from $18 \mathrm{Jan}$ uary 2012 to 26 December 2012. This corresponds to 50 analyses with an assimilation cycle of 7 days. The three experiments assimilate SLA and SST data and differ only as regards the in situ assimilated data sets:

- The experiment entitled Run-Ref assimilates SLA, SST and all in situ data (Argo + "non-Argo in situ data").

- The experiment entitled Run-Argo2 assimilates SLA, SST, $50 \%$ of the Argo data and all the "other No Argo in situ data".

- The experiment entitled Run-NoArgo assimilates SLA, SST and all "other No Argo in situ data".

For the three experiments above, the strategy is to start from the same initial conditions of the PSY3 operational system that assimilates all the data and then withdraw part of the Argo data set for the OSEs. Lastly, a free run (i.e., where no data at all are assimilated), hereafter called Free Run, was also carried out to assess the overall improvement of the PSY3 system. The free run starts from the same initial conditions as for the three above-mentioned experiments. Table 1 summarizes the experiment strategy.

\section{Results}

This section is organized as follows. The first part is an independent comparison of the Run-NoArgo analyzed fields with Argo observations. The second part compares analyzed temperature and salinity fields from the different OSEs. This quantifies the amplitude and the spatial distribution of the changes bring by the assimilation of Argo profiles. We then 

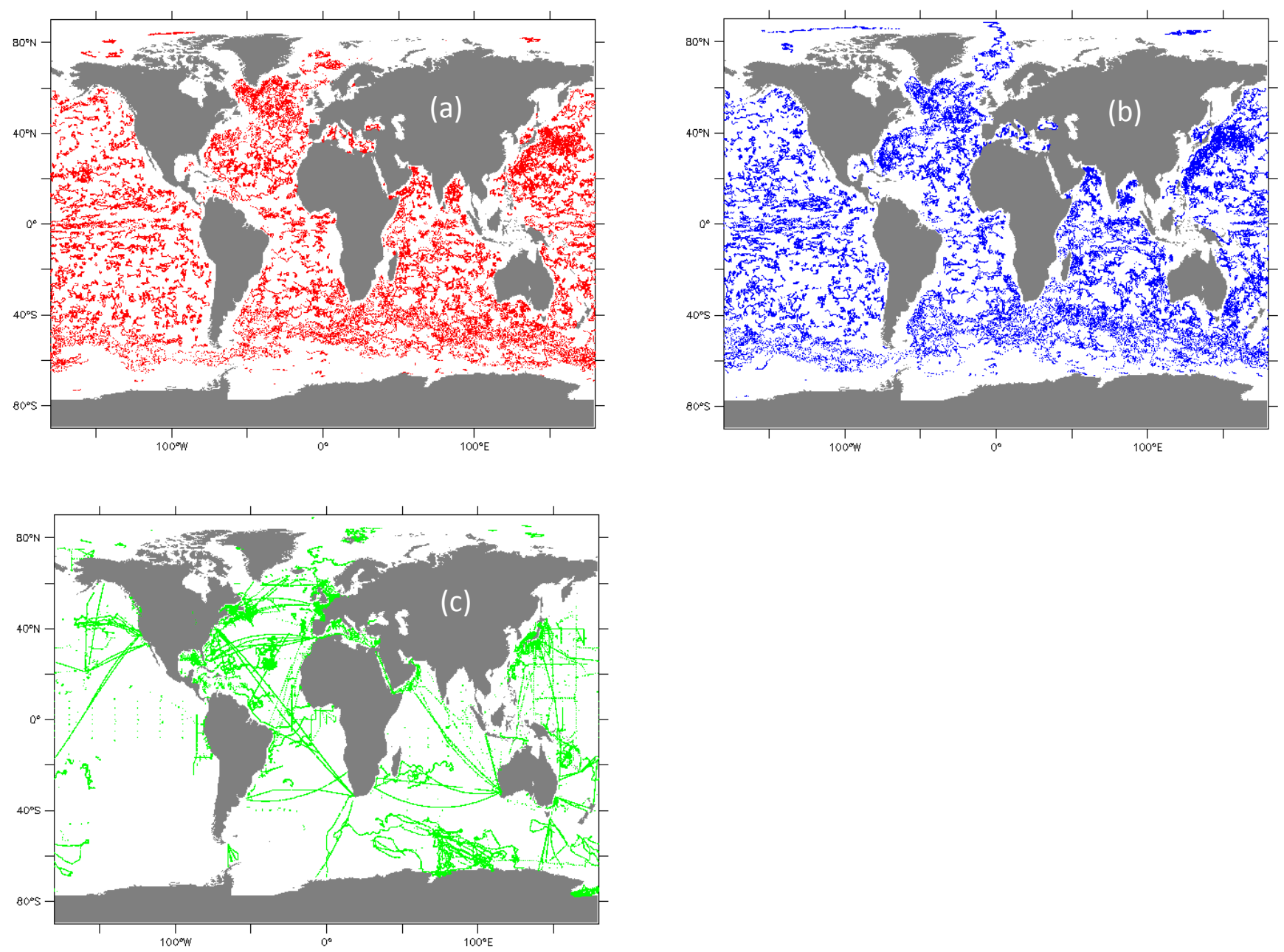

Figure 1. Spatial distribution of 2012 in situ data set divided into three sub-data sets. Red dots are the Argo profiles from odd WMO (World Meteorological Organization) platform numbers, blue dots are Argo profiles from even WMO platform numbers, green dots are the other in situ observations.

verify that those changes in the analyzed fields correspond to a decrease of the misfit to in situ observations when Argo profiles are assimilated. The last part compares Argo observations with co-located profiles from forecasted fields to assess the impact of the Argo data assimilation. In each subsection, temperature and salinity results are discussed separately. The impact on the sea surface height and sea surface temperature innovations is also briefly discussed.

Statistics are done over the last 6 months of each year of OSE experiments in order to avoid the spin-down period due to the initialization of the OSEs with an analyzed field where all Argo observations were previously assimilated. This period appears to be sufficient for the temperature field to reach a stable state compared to observations, but the deep ocean still shows a small drift in salinity. This spin-down time is still difficult to evaluate in 1-year simulations where the evolution of the $T$ and $S$ misfits are superimposed to their seasonal variations. A 1-year simulation would not be a good ap- proach if considering the impact of Argo on long-term ocean reanalysis; here we stay in the context of short-term real-time ocean analysis and forecasts. Comparison of Run-NoArgoassimilated fields with Argo observations

Figure 3 shows the spatial distribution of the mean and RMS (root mean square) of the temperature difference between Argo observations and the Run-NoArgo analysis. RMS and mean statistics are calculated in $2^{\circ} \times 2^{\circ}$ boxes and in the 0-300 and 700-2000 m layers.

Figure $3 \mathrm{a}$ shows that, in the $0-300 \mathrm{~m}$ layer, our model without Argo data assimilation fails to correctly represent temperature fields over large regions. As expected, errors are also larger in western boundary currents and in the thermocline in the tropics where a small misplacement leads to large temperature errors due to the sharpness of the thermocline. The RMS of the differences between analyzed fields and Argo observations in these regions reaches $1.5^{\circ} \mathrm{C}$. Midlatitude gyres in the Atlantic, Pacific and Indian oceans have 

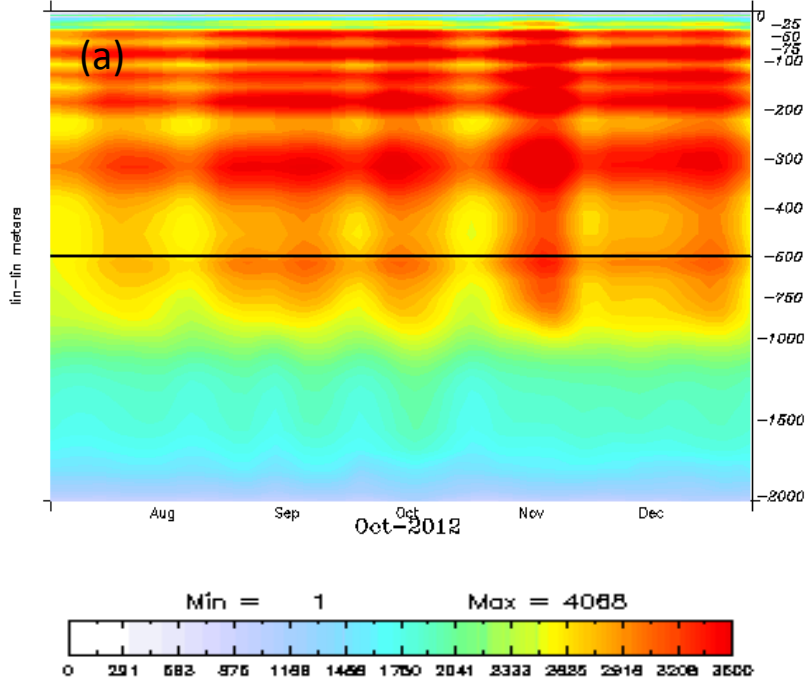
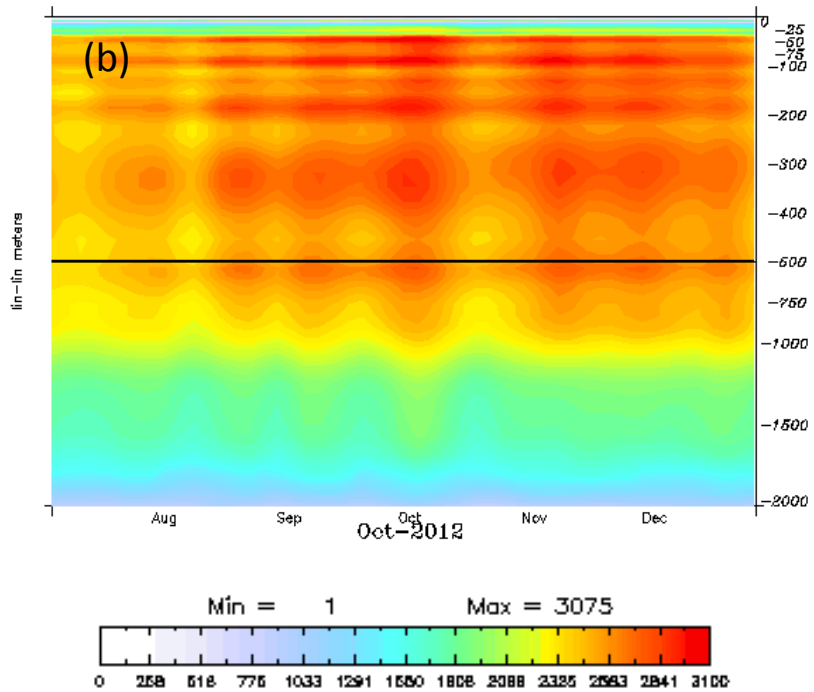

Figure 2. Time series of the number of 2012 in situ temperature (a) and salinity (b) data items from the surface to $2000 \mathrm{~m}$ per week.
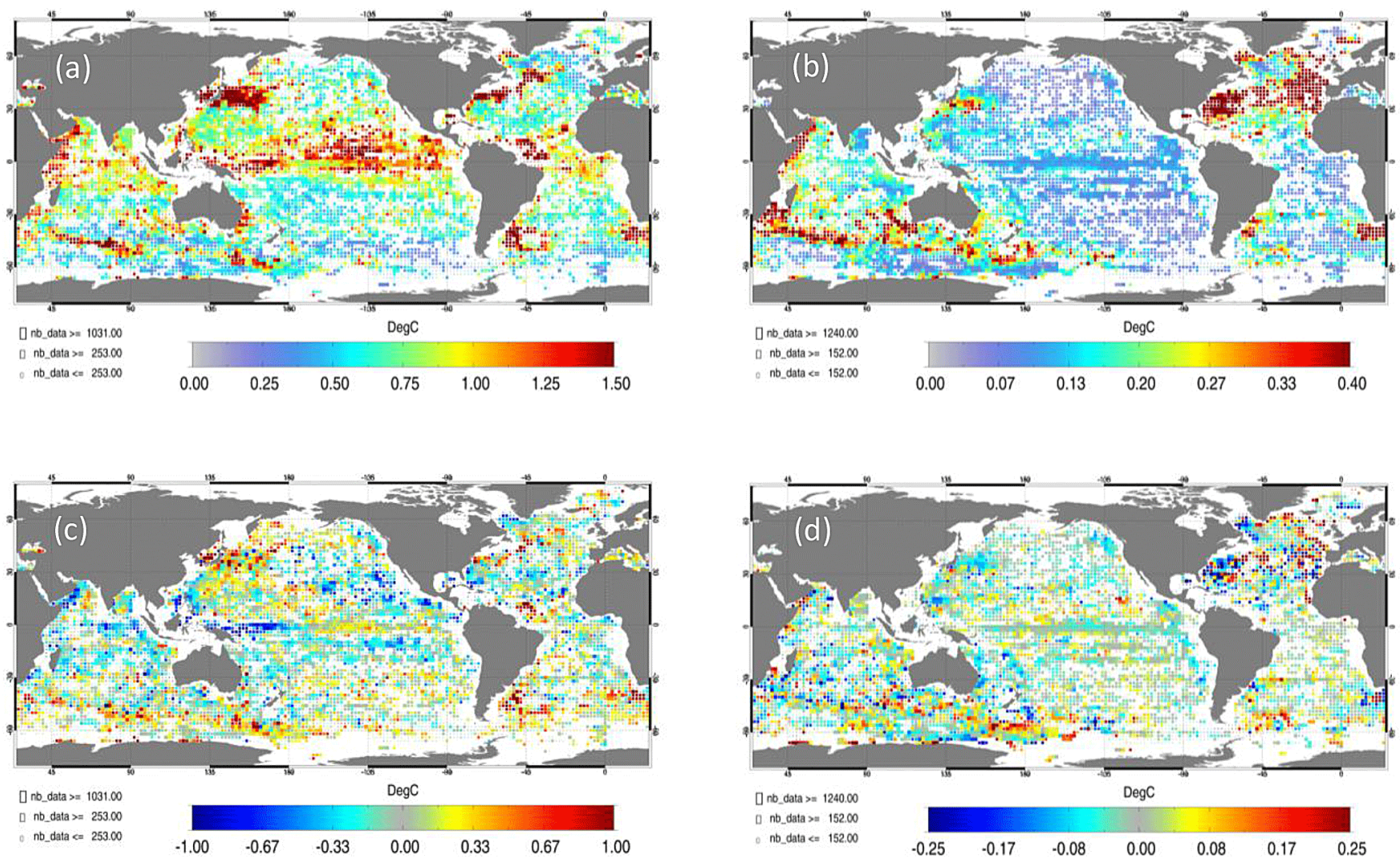

Figure 3. Spatial distribution of the RMS and the mean temperature differences between Run-NoArgo and Argo observations in the 0-300 and 700-2000 m layers over the last 6 months of the experiments. (a) shows the RMS temperature differences in the $0-300 \mathrm{~m}$ layer. (b) shows the RMS temperature differences in the 700-2000 m layer. (c) shows the mean temperature differences in the 0-300 $\mathrm{m}$ layer. (d) shows the mean temperature differences in the 700-2000 $\mathrm{m}$ layer. The size of the colored boxes is proportional to the number of observations falling into that $2^{\circ} \times 2^{\circ}$ box. 

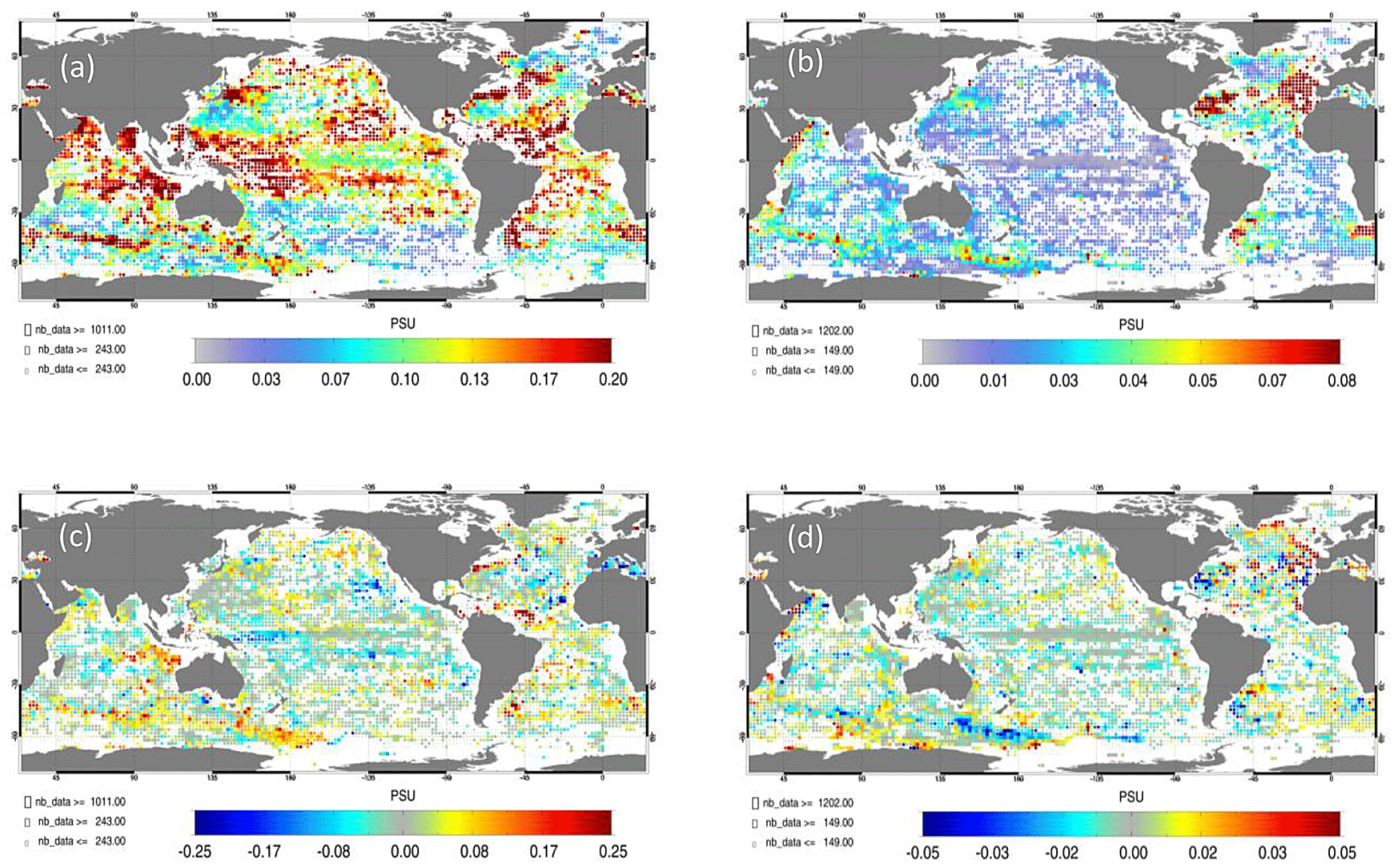

Figure 4. Spatial distribution of the mean and RMS salinity differences between Run-NoArgo and Argo observations in the 0-300 and 700-2000 m layers over the last 6 months of the experiments. (a) shows the RMS salinity differences in the 0-300 $\mathrm{m}$ layer. (b) shows the RMS salinity differences in the 700-2000 m layer. (c) shows the mean salinity differences in the 0-300 m layer. (d) shows the mean salinity differences in the 700-2000 m layer. The size of the colored boxes is proportional to the number of observations falling into that $2^{\circ} \times 2^{\circ}$ box.
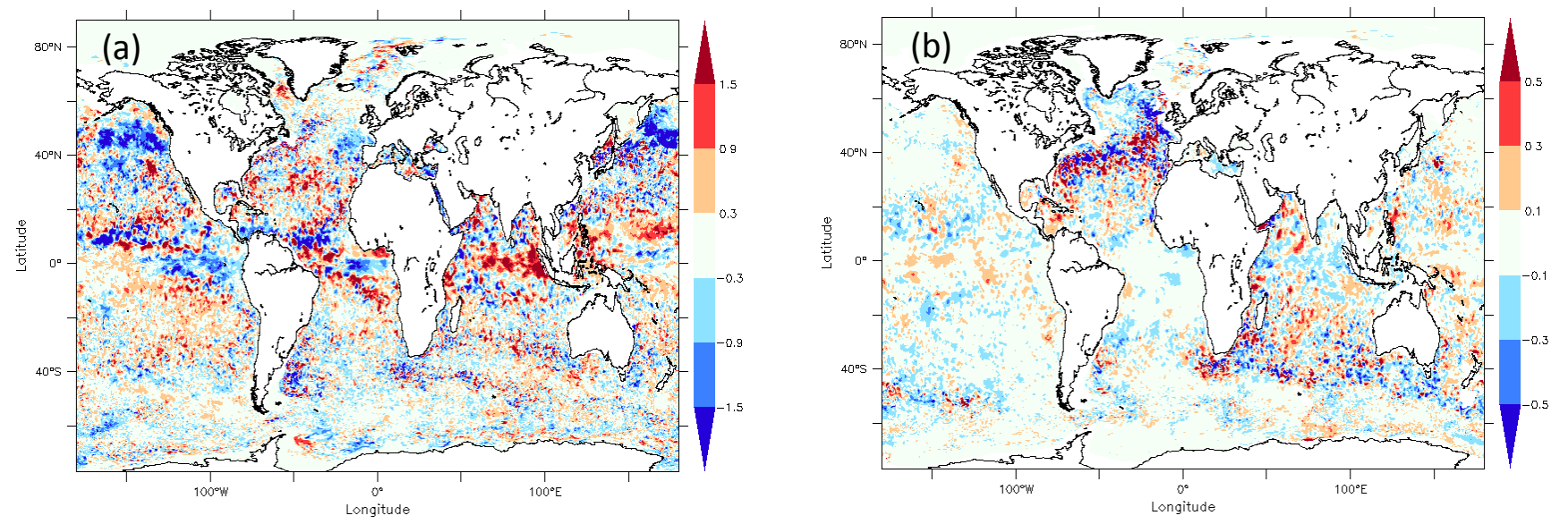

Figure 5. 19 December 2012: analyzed temperature fields - differences between Run-Ref and Run-NoArgo at $100 \mathrm{~m}$ (a) and $1000 \mathrm{~m}$ (b).

smaller errors. However, the RMS in these regions is still around $0.75^{\circ} \mathrm{C}$. The mean of the differences between the analyzed field and the observations is calculated on a similar basis as the RMS. The mean of the temperature differences reveals that without Argo assimilation, western bound- ary currents are $0.5^{\circ} \mathrm{C}$ warmer than observations. The tropical Pacific Ocean is cooler $\left(-0.6^{\circ} \mathrm{C}\right)$ than Argo observations in the western part.

In the 700-2000 m layer, errors are more spatially concentrated. The RMS differences between Run-NoArgo-analyzed 

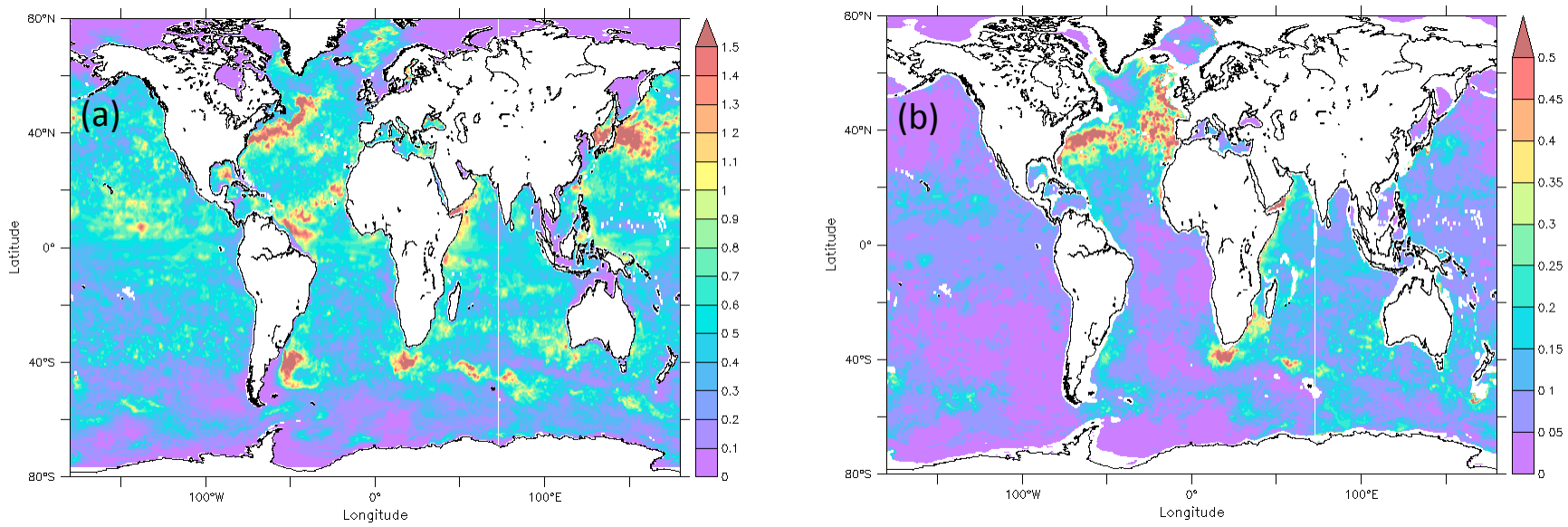

Figure 6. The RMS of temperature differences between Run-Ref and Run-NoArgo in the 0-300 m layer (a) and in the 700-2000 $\mathrm{m}$ layer (b) for the last 6 months of the experiments.
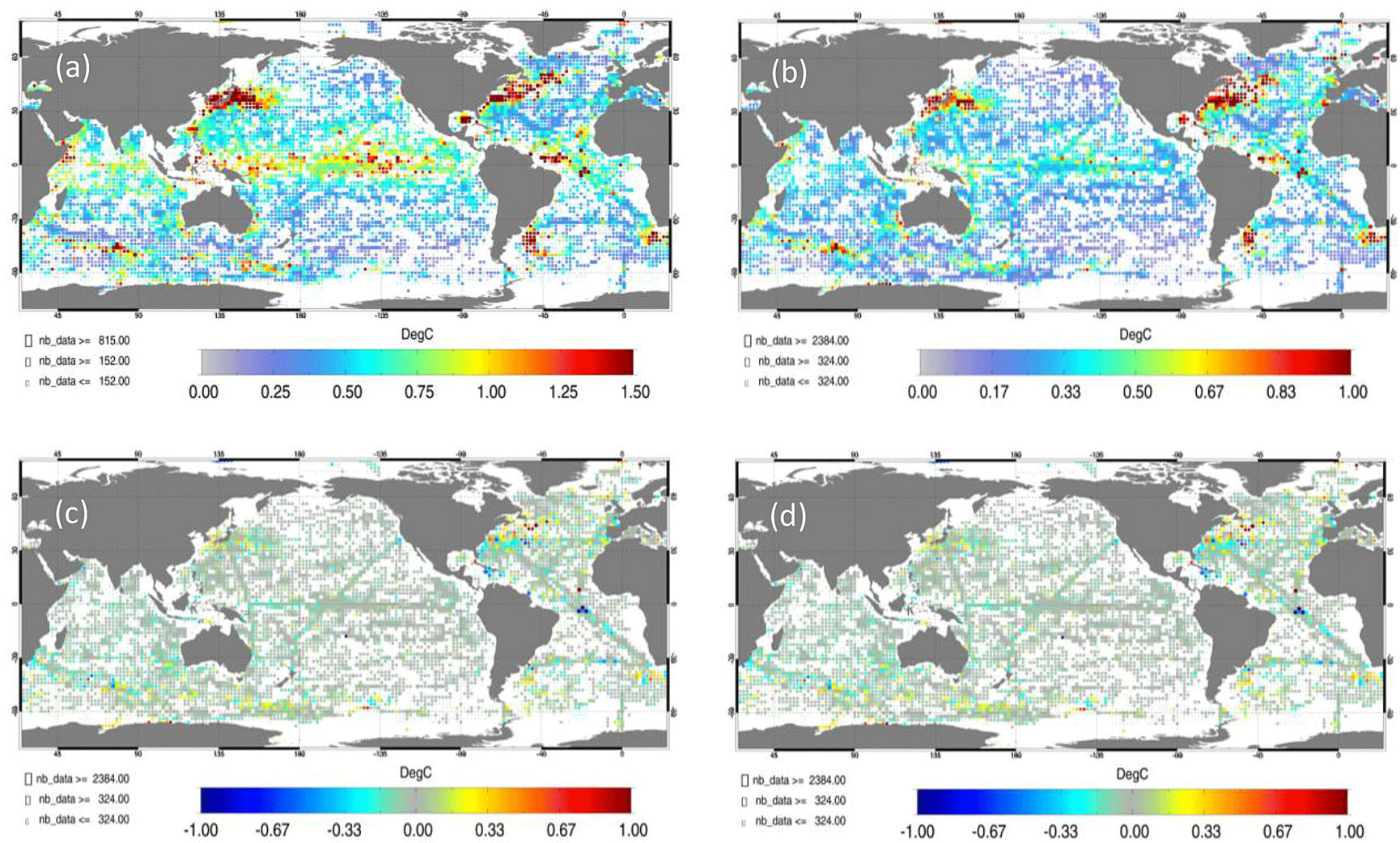

Figure 7. Spatial distribution of the mean and RMS temperature differences between Run-Ref and in situ observations in the 0-300 and 700-2000 m layers over the last 6 months of the experiments. (a) shows the RMS temperature differences in the $0-300 \mathrm{~m}$ layer. (b) shows the RMS temperature differences in the 700-2000 m layer. (c) shows the mean temperature differences in the 0-300 $\mathrm{m}$ layer. (d) shows the mean temperature differences in the 700-2000 $\mathrm{m}$ layer. The size of the colored boxes is proportional to the number of observations falling into that $2^{\circ} \times 2^{\circ}$ box.

fields and Argo observations in the western boundary currents is over $0.25^{\circ} \mathrm{C}$ but can reach $0.4^{\circ} \mathrm{C}$ in particular areas. The analyzed temperature of the regions between the Southern and Indian oceans are also very different from Argo measurements. The North Atlantic and the Arabian Sea show RMS temperature differences of 0.4 and $0.2^{\circ} \mathrm{C}$ respectively. In the tropics, the RMS reaches $0.15^{\circ} \mathrm{C}$. In the middle of the Pacific subtropical basin, the contribution of Argo assimila- 

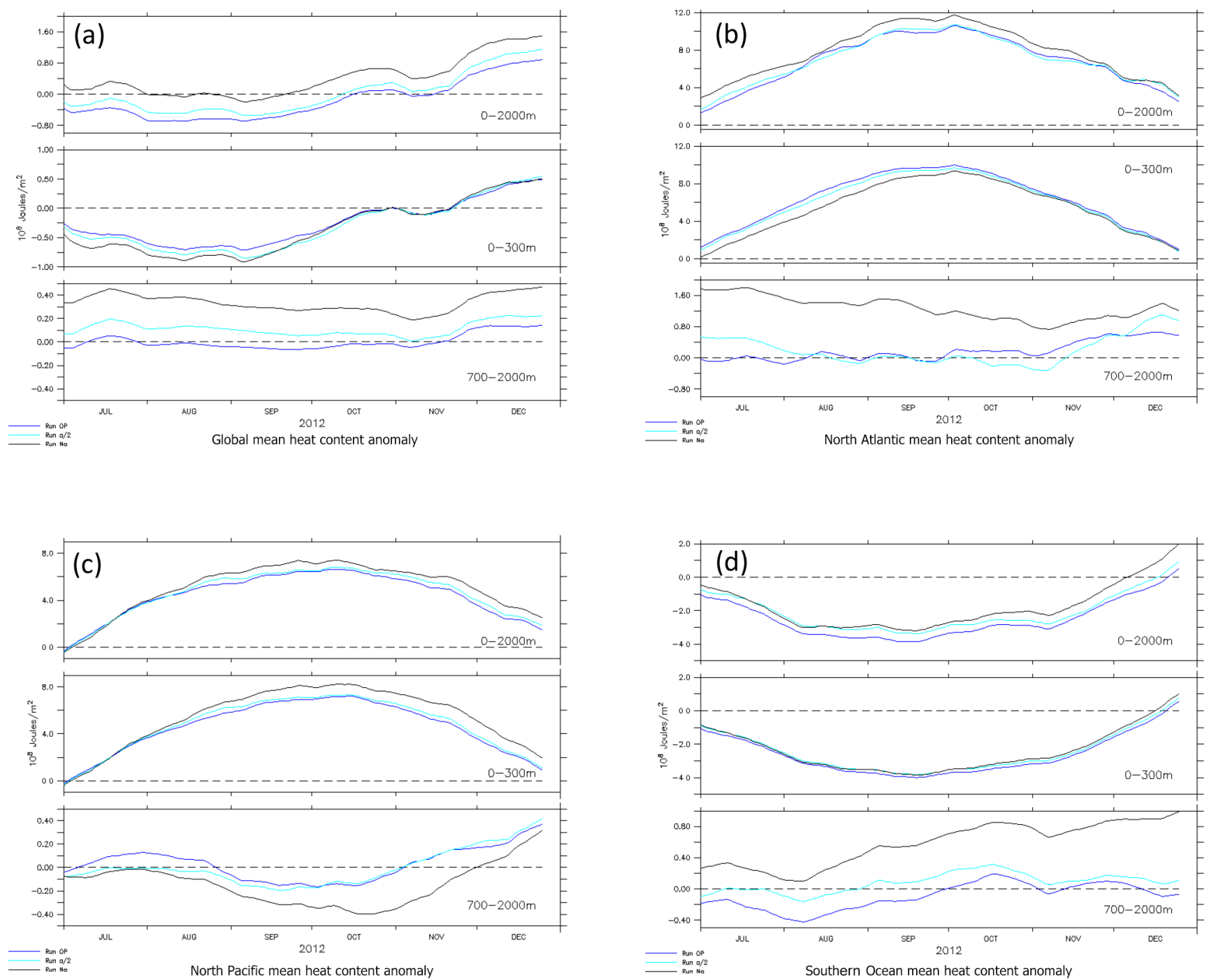

Figure 8. Heat content anomaly time series for the 0-2000, 0-300 and 700-2000 m layers of the Run-Ref (blue), Run-Argo2 (light blue) and Run-NoArgo (black): (a) for the global ocean, (b) North Atlantic, (c) North Pacific and (d) Southern Ocean.
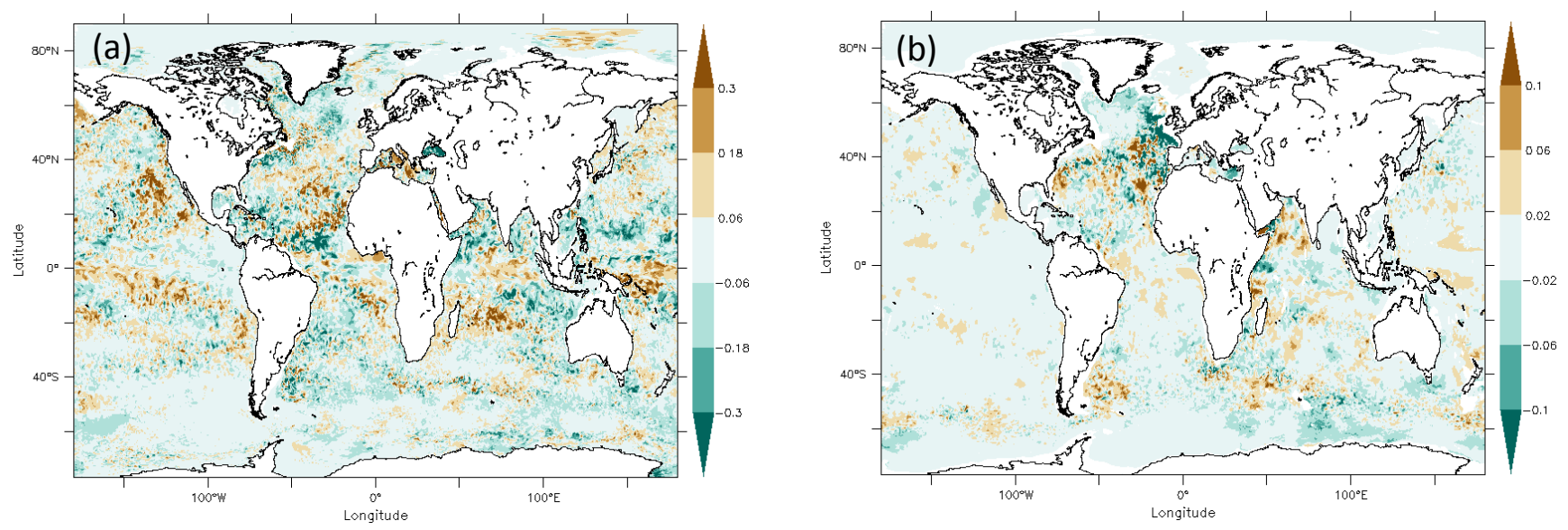

Figure 9. 19 December 2012, analyzed salinity fields - differences between Run-Ref and Run-NoArgo at $100 \mathrm{~m}$ (a) and $1000 \mathrm{~m}$ (b). 

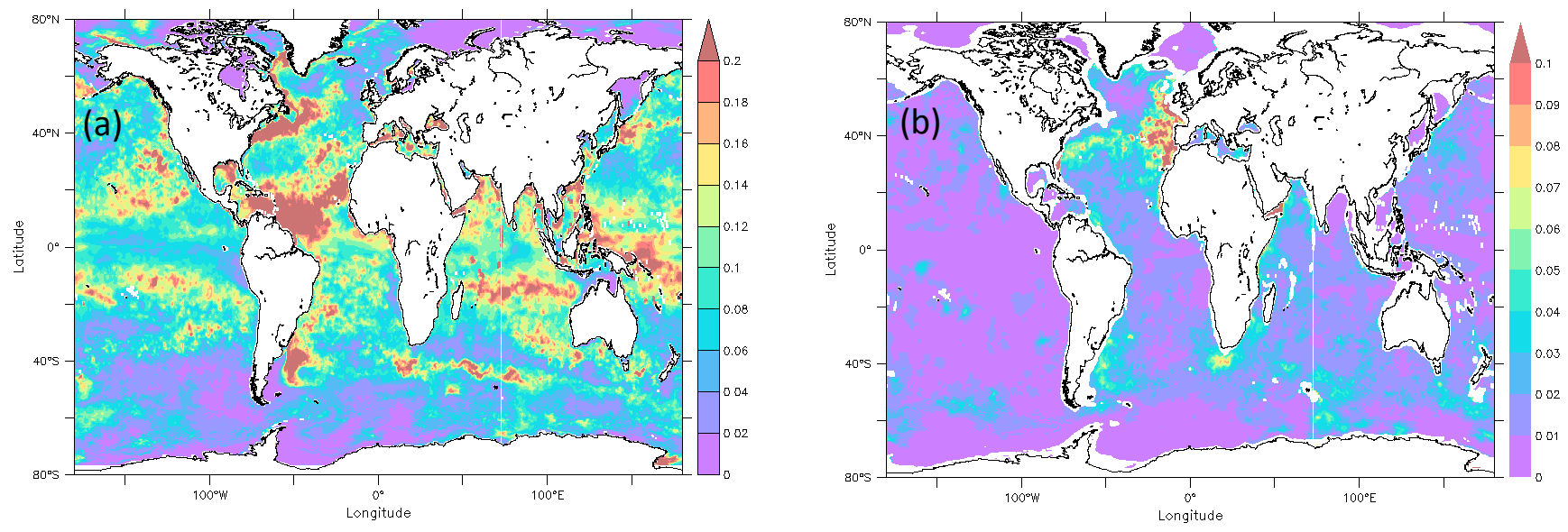

Figure 10. RMS of salinity differences between Run-Ref and Run-NoArgo in the 0-300 and 700-2000 m layers for the last 6 months of the experiment.
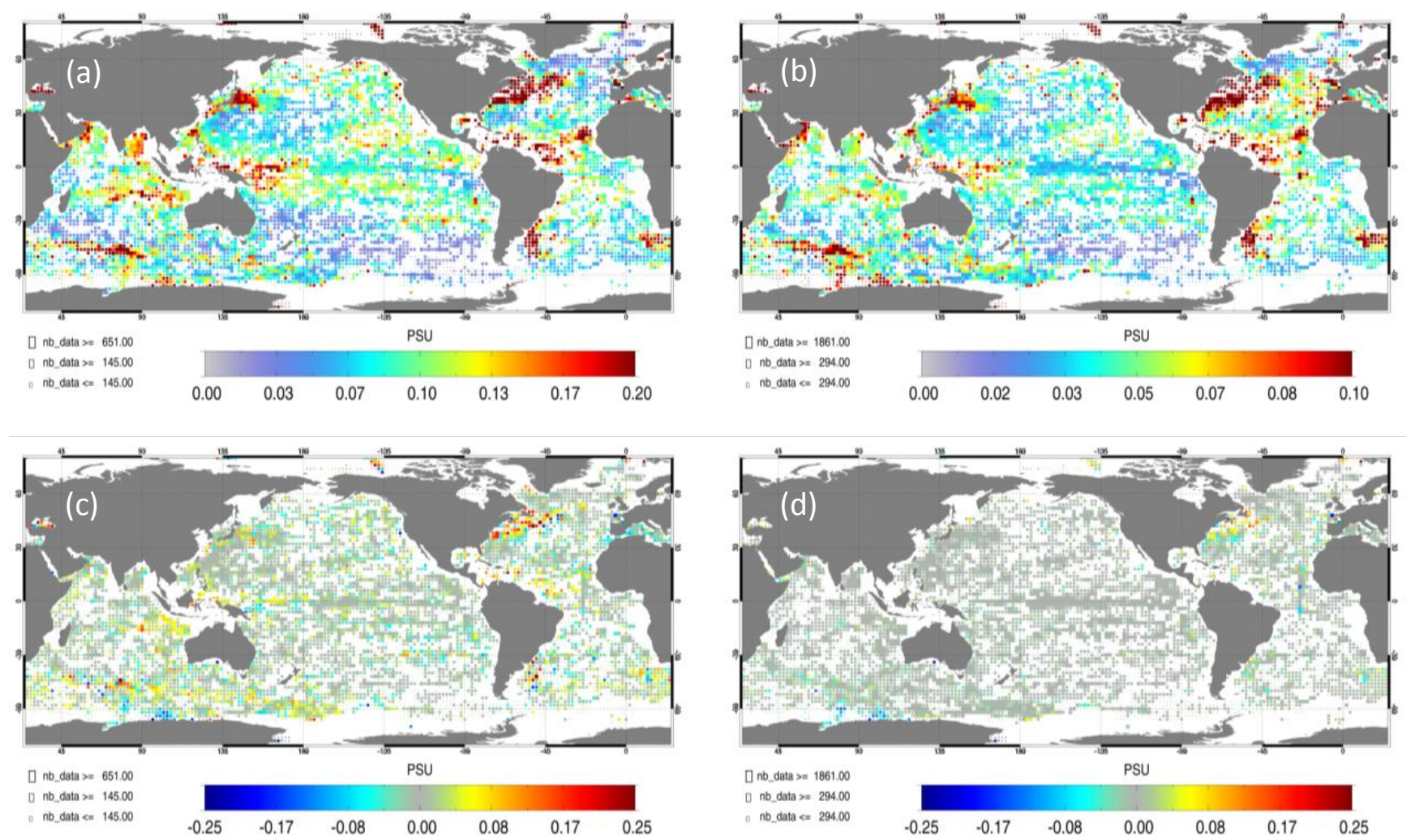

Figure 11. Spatial distribution of the RMS and the mean salinity differences between Run-Ref and in situ observations in the 0-300 and 700-2000 m layers over the last 6 months of the experiments. (a) shows the RMS salinity differences in the 0-300 m layer. (b) shows the RMS salinity differences in the 700-2000 m layer. (c) shows the mean salinity differences in the 0-300 m layer. (d) shows the mean salinity differences in the 700-2000 m layer. The size of the colored boxes is proportional to the number of observations falling into that $2^{\circ} \times 2^{\circ}$ box.

tion is less obvious, as the RMS in that part of the ocean is lower than $0.1^{\circ} \mathrm{C}$. The mean misfit does not reveal any significant bias for that layer in this region.

Figure 4 is similar to the previous figure but concerns salinity. Figure 4a shows the RMS differences between an- alyzed salinity and Argo observations in the 0-300 m layer. At that depth, mid-latitude oceans, northern Indian Ocean, North Pacific, Atlantic, western boundary current regions and part of the Southern Ocean show differences larger than $0.1 \mathrm{psu}$ and could be considered as regions very sensitive to 

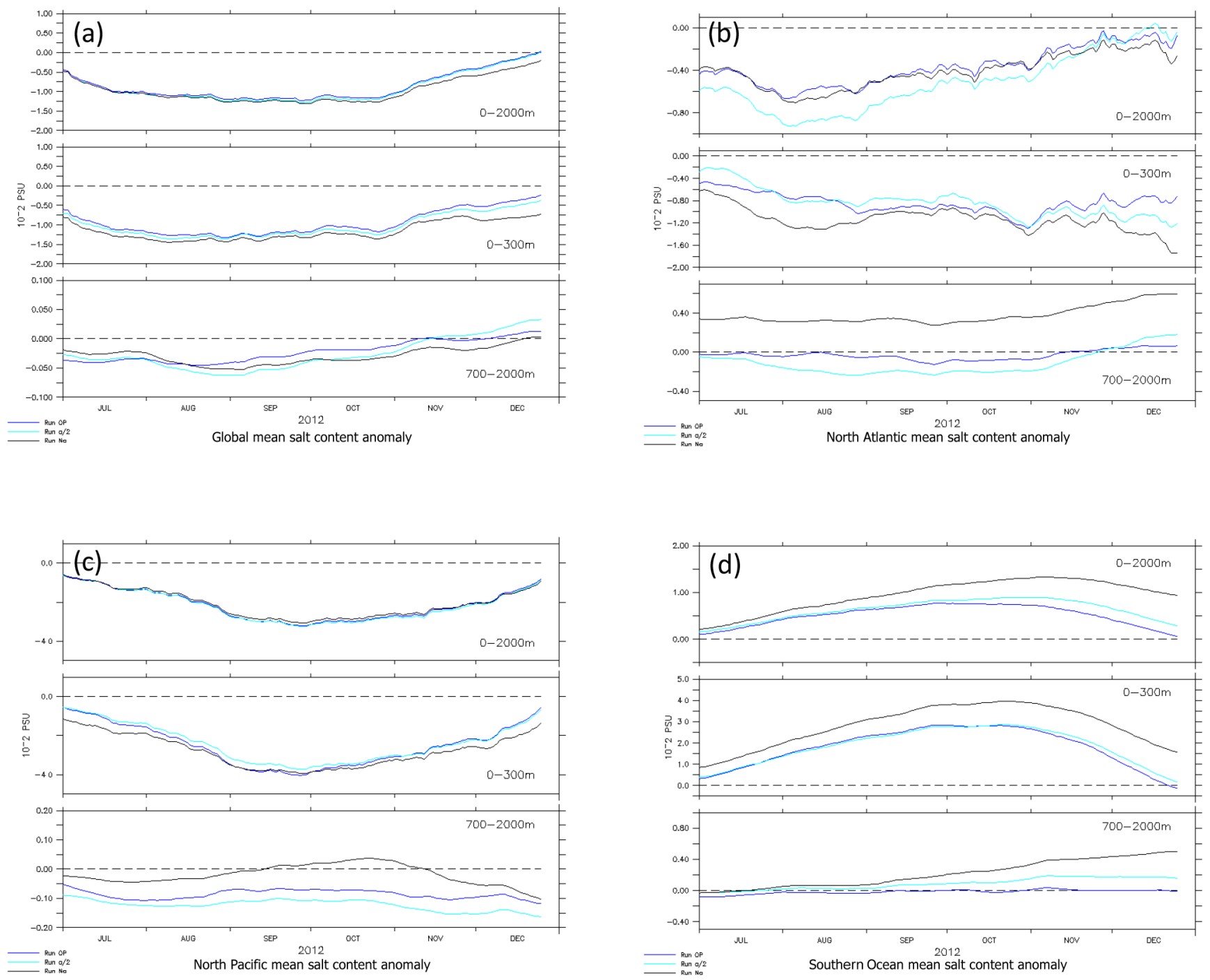

Figure 12. Salt content anomaly time series for the 0-2000, 0-300 and 700-2000 m layers from Run-Ref (blue), Run-NoArgo (black), and Run-Argo2 (light blue) and for the global ocean (a), North Atlantic (b), North Pacific (c), and Southern Ocean (d).

salinity observations, unlike the South Pacific, southern Indian Ocean and part of the Southern Ocean. The distribution of the mean salinity differences (Fig. 4c) shows particular patterns in the Southern Ocean between South Africa and Australia, in the eastern Indian Ocean and also in the South Atlantic. The analyzed ocean in these regions displays a strong positive salt bias.

From 700 to $2000 \mathrm{~m}$ (Fig. 4b), the North Atlantic basin, outflow regions, western boundary current regions and part of the Southern Ocean between South Africa and Australia have large RMS misfits. In this layer, the mean salinity misfit is greatest in the Southern Ocean and Mediterranean outflow region (Fig. 4d). In this depth range, the analysis is likely to be sensitive to Argo assimilation as there are very few other in situ data to constrain it.

\subsection{Impact of Argo data assimilation on analyzed fields}

In the next two subsections, we discuss the differences in analyzed temperature and salinity fields from the surface down to a depth of $2000 \mathrm{~m}$ due to the Argo data set assimilation. In each subsection, we study a snapshot of the daily difference between OSEs with and without Argo data assimilation to illustrate the effect of Argo data assimilation. We then use the spatial RMS of the daily differences in the 0-300 and 700$2000 \mathrm{~m}$ layers to provide quantitative information on the realism of the analyzed $T$ and $S$ fields compared to in situ observations. Heat and salt content in the 0-2000, 0-300 and 700-2000 m layers are also analyzed. This shows the sensitivity of the analyzed temperature and salinity fields to Argo data assimilation. We then verify that the in situ observation- 
analysis differences were efficiently reduced by the assimilation process.

\subsubsection{Temperature}

Figure 5 shows the temperature differences between Run-Ref and Run-NoArgo for 19 December 2012 at 100 and $1000 \mathrm{~m}$. We chose that date to illustrate the state of the analyzed ocean at the end of a year-long experiment.

The impacts of Argo observations at $100 \mathrm{~m}$ (Fig. 5a) are widely but unequally distributed in the global ocean. Many regions show differences higher than $0.3^{\circ} \mathrm{C}$, mostly in the Northern Hemisphere and in the equatorial band. In some regions, these 1-day differences reach $1{ }^{\circ} \mathrm{C}$ or more.

At $1000 \mathrm{~m}$ the influence of Argo observations is much more localized: analyses for the North Atlantic, Agulhas Current, south of Australia and southern Indian Ocean are strongly affected by Argo assimilation. In these highly dynamic regions, differences between the two experiments reach $0.5^{\circ} \mathrm{C}$. The influence of Argo observations at $1000 \mathrm{~m}$ is striking in the North Atlantic area of the outflow from the Mediterranean: differences there can be larger than $0.3^{\circ} \mathrm{C}$. As a consequence, Argo data assimilation is crucial to correct the water mass properties in the ocean interior of the model forecast.

Figure 6 shows the RMS of the temperature differences between Run-Ref and Run-NoArgo. It is calculated from the daily differences of the last 6 months of the experiment. It quantifies the spatial distribution of the impact of Argo assimilation on the PSY3 data assimilation system. We chose to focus on the $0-300 \mathrm{~m}$ layer, where SST and SLA assimilation also plays a major role, in order to evaluate the importance of Argo temperature measurements in the upper ocean, and on the 700-2000 m layer to assess the impact of Argo profiles in this specific layer, where Argo is almost the only in situ observing system available.

Figure 6a shows that global ocean analyses are impacted by assimilating the Argo data in the $0-300 \mathrm{~m}$ layer. The RMS of the temperature differences between experiments reaches $0.5^{\circ} \mathrm{C}$ in each ocean. The highest values of the RMS (around $1.5^{\circ} \mathrm{C}$ ) are located in regions where the variability is very high (i.e., Gulf Stream, Kuroshio, Brazilian Current, Agulhas Current, and North Brazil Current retroflection). Argo assimilation in these regions strongly impacts analyzed temperature fields.

In the 700-2000 m layer (Fig. 6b), the impact of Argo on analyzed temperature fields is more localized in regions with high variability. In the Gulf Stream, the Agulhas Current and around South Africa the RMS of the temperature differences reaches $0.5^{\circ} \mathrm{C}$. In this depth range, the North Atlantic remains the most sensitive region to Argo data assimilation. The RMS of the temperature differences in the Red Sea and Mediterranean outflow region is around $0.5^{\circ} \mathrm{C}$. On the other hand, the impact of Argo in the 700-2000 m layer is not as widely dispersed as in the $0-300 \mathrm{~m}$ layer. The RMS remains significant (around $0.2^{\circ} \mathrm{C}$ ) in the South Atlantic, Indian Ocean and part of the Southern Ocean. Pacific Ocean analyses in that layer are less impacted by the assimilation of Argo data.

The map of RMS differences in the layer 300-700 m (not shown here) exhibits similar patterns to the $0-300 \mathrm{~m}$ layer but with smaller amplitudes.

Figure 7 shows the spatial distribution of the mean and RMS of the temperature differences between Argo observations and the Run-Ref analysis which assimilates Argo observations with satellite and other in situ observations. The RMS and mean statistics are calculated in $2^{\circ} \times 2^{\circ}$ boxes and in the 0-300 and 700-2000 m layers. Differences are obviously much reduced compared to the Run-NoArgo experiment (Fig. 3), which shows that the assimilation system is able to retain most of the information derived from Argo observations and there is no significant incompatibility with the other assimilated data sets (e.g., satellite altimetry). In what follows, Run-Ref will be considered our best estimate of the real ocean and we will further quantify the impact of Argo observations by comparing the analyzed Run-Argo2 and Run-NoArgo fields to the Run-Ref fields.

Figure 8 shows the time series of heat content anomaly estimates in different oceans and for different depth ranges. Heat content changes are calculated as described in Von Schuckmann et al. (2009). Anomalies are obtained by subtracting the 3-year mean (2011-2013) of PSY3-analyzed fields from the OSE's analyzed temperature. Time series for the global ocean, the North Atlantic $\left(20-60^{\circ} \mathrm{N}, 5-70^{\circ} \mathrm{W}\right)$, North Pacific $\left(20-60^{\circ} \mathrm{N}, 110^{\circ} \mathrm{W}-120^{\circ} \mathrm{E}\right)$ and Southern Oceans $\left(50-70^{\circ} \mathrm{S}, 180^{\circ} \mathrm{W}-180^{\circ} \mathrm{E}\right)$ are shown in Fig. 8.

The global ocean heat content (hereafter referred to as GOHC) anomaly is an important diagnostic measure of changes in Earth's climate system (Levitus et al., 2005; Hansen et al., 2005). This diagnostic measure is often derived from Argo observations (e.g., Von Schuckmann et al., 2011, 2009; Willis et al., 2009; Trenberth and Fasullo, 2010) or other observing systems such as altimetry or through the closure of Earth's energy budget (e.g., Domingues et al., 2008; Cazenave and Llovel, 2010; Trenberth and Fasullo, 2010).

Figure 8a shows an overestimation of the GOHC anomaly calculated without Argo observations that is significant compared to the variability of the system. In the $0-2000 \mathrm{~m}$ layer, the GOHC anomaly difference between Run-Ref and RunNoArgo is around $0.8 \times 10^{8} \mathrm{~J} \mathrm{~m}^{-2}$. The anomaly for the three OSEs varies from $-1 \times 10^{8}$ to $2 \times 10^{8} \mathrm{~J} \mathrm{~m}^{-2}$. This difference is mainly driven by the estimation of the heat content anomaly in the 700-2000 $\mathrm{m}$ layer where the discrepancy between experiments reaches $0.4 \times 10^{8} \mathrm{~J} \mathrm{~m}^{-2}$. In the $0-300 \mathrm{~m}$ layer, the differences between the OSEs are less significant.

Focusing on different ocean regions (Fig. 8b, c, d) shows that the impact of Argo differs depending on regions and hemispheres. In the North Atlantic Ocean, in the 7002000 m layer, ocean analysis without Argo observation gives warmer results than our best ocean estimate. The heat con- 


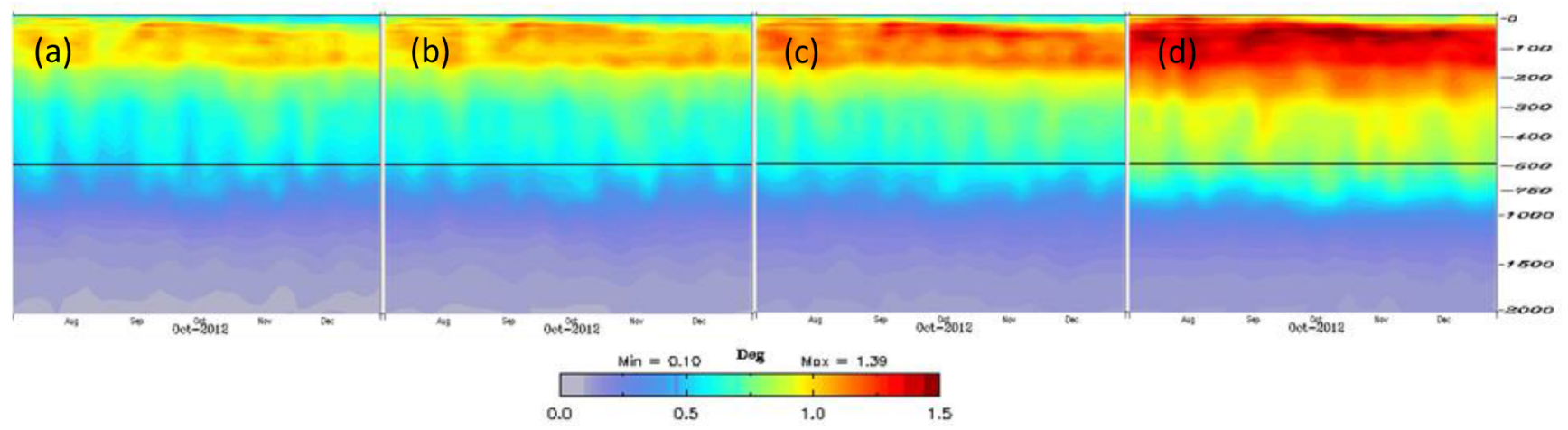

Figure 13. RMS time series of the temperature innovations for Run-Ref (a), Run-Argo2 (b), Run-NoArgo (c) and Free Run (d) in the last 6 months of the experiments.
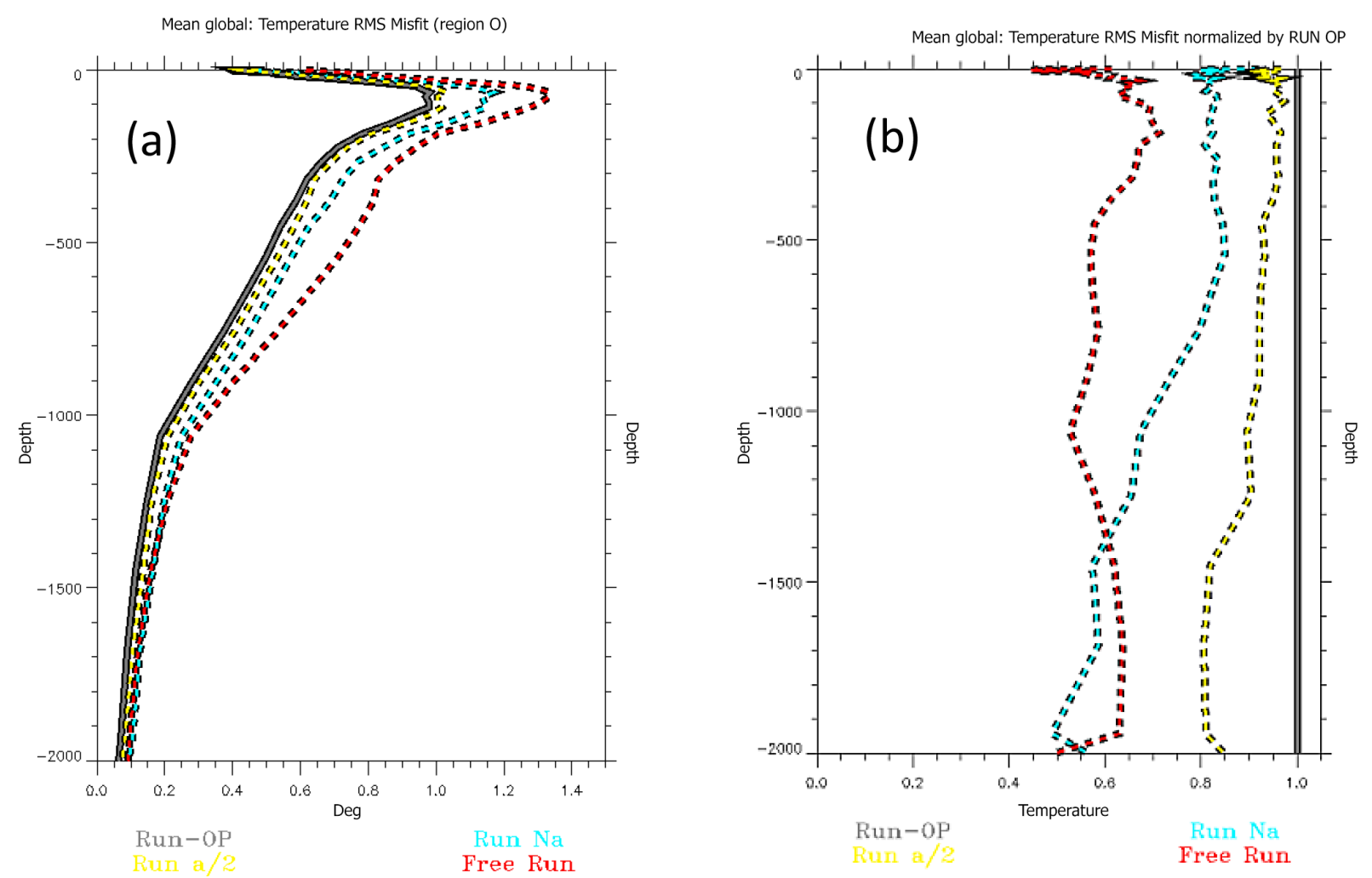

Figure 14. Vertical structure of the RMS of temperature innovations (a) and normalized RMS of temperature innovations (b) from 0-2000 m for Run-Ref (grey), Run-Argo2 (yellow), Run-NoArgo (blue) and Free Run (red) over the last 6 months of the experiments.

tent anomaly reaches $1.4 \times 10^{8} \mathrm{~J} \mathrm{~m}^{-2}$, which is significant when compared to the heat content variability there. It is also noticeable that the impact is not necessarily in the same direction. Contrary to the North Atlantic Ocean and the South Oceans, heat content anomaly is reduced without Argo assimilation in the North Pacific Ocean in the 700-2000m layer. Moreover, the negative heat content anomaly leads to compensation between the heat content anomalies in differ- ent oceans that hide the importance of Argo observations in the GOHC evaluation.

These experiments show the high sensitivity of the ocean heat content estimation from the PSY3 analysis to the assimilation of the Argo observation array. This is especially true for depths below $700 \mathrm{~m}$, where the variability is smaller than in the surface layer. Estimates differ if only half of the Argo floats are assimilated. 


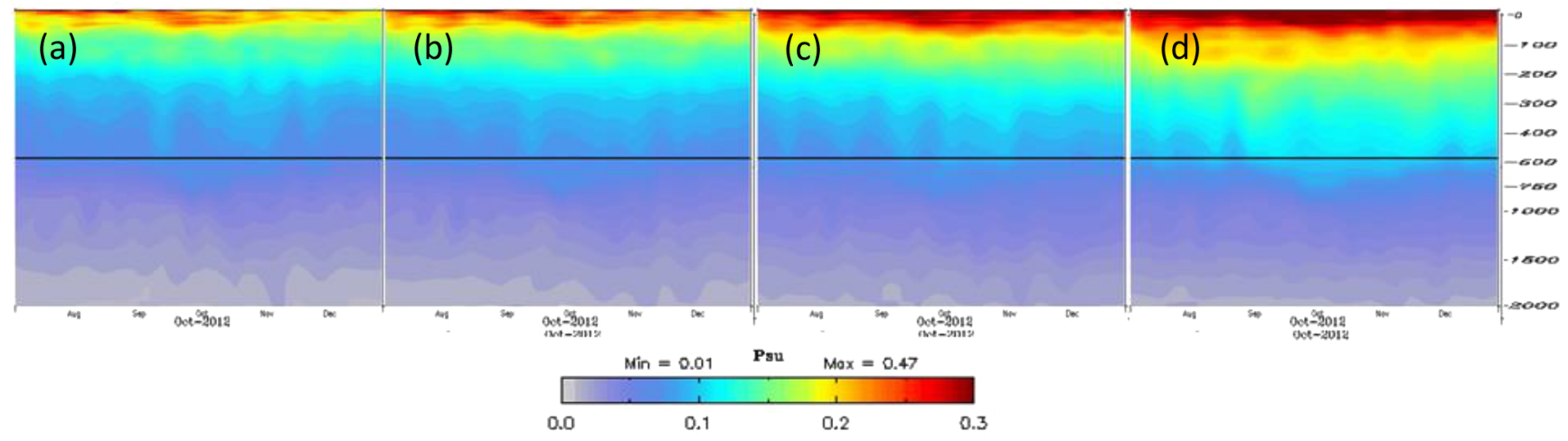

Figure 15. RMS time series of the salinity forecast field and in situ salinity differences for Run-Ref (a), Run Argo2 (b), Run-NoArgo (c) and Free Run (d) in the last 6 months of the experiments.
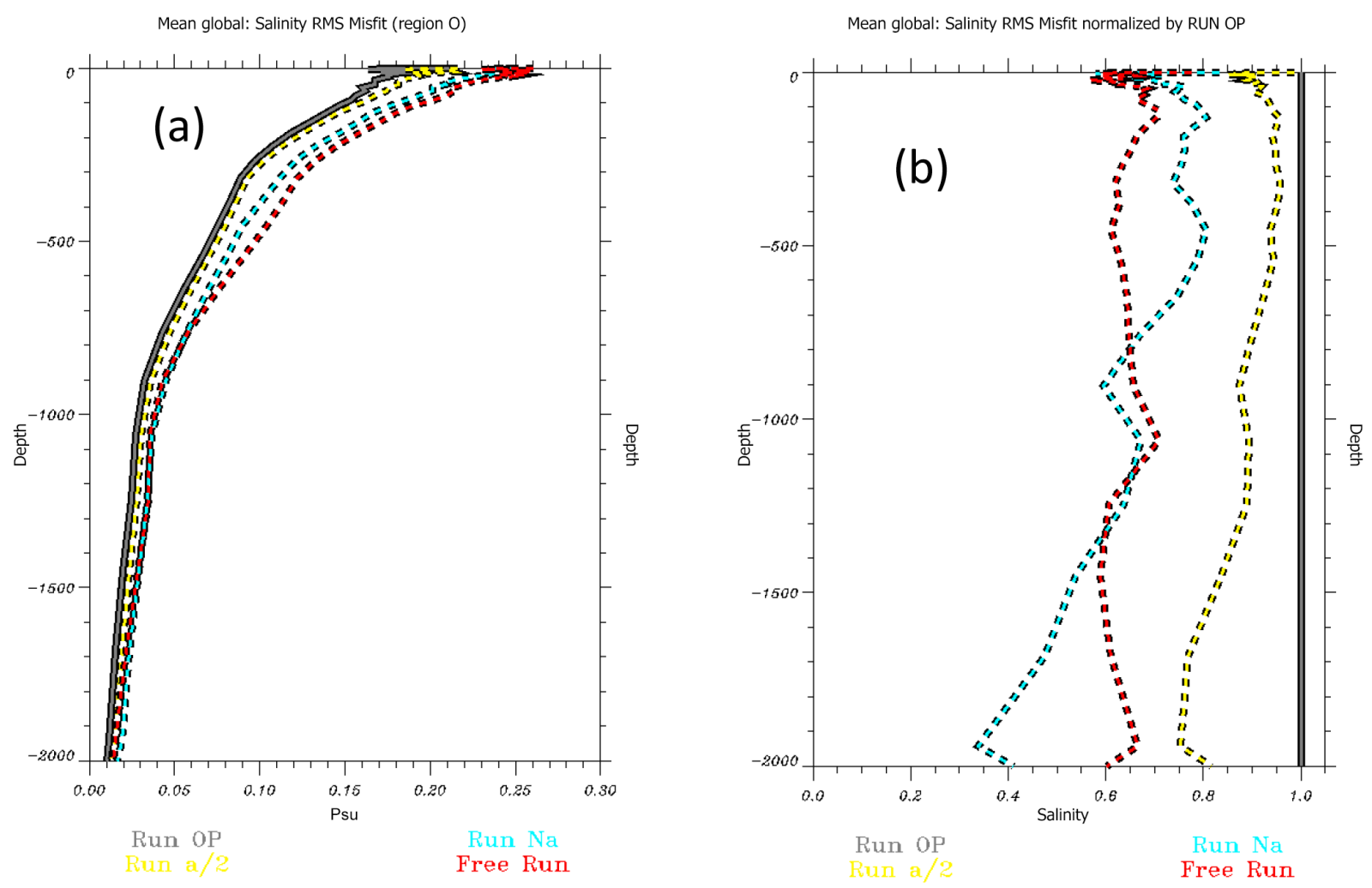

Figure 16. Vertical structure of the RMS of salinity innovations (a) and normalized RMS of salinity innovations (b) from 0 to $2000 \mathrm{~m}$ for Run-Ref (grey), Run-Argo2 (yellow), Run-NoArgo (blue) and Free Run (red) over the last 6 months of the experiments.

\subsubsection{Salinity}

Figure 9 shows the salinity differences between Run-Ref and Run-NoArgo for 19 December 2012 at 100 and $1000 \mathrm{~m}$. At $100 \mathrm{~m}$, significant differences are spread all over the global ocean. Many regions are heavily affected by Argo assimilation, such as the tropical oceans and the Gulf Stream area. Around the Equator, the maximum amplitude of the daily differences is larger than 0.3 psu. The spread and amplitude of differences show the sensitivity of the PSY3 analysis to the assimilation of Argo salinity data.

At $1000 \mathrm{~m}$, North Atlantic regions are very sensitive to the assimilation of Argo profiles, the differences reach 0.1 psu. The impact is greatest in the Mediterranean and Red Sea outflows and in the Gulf Stream areas. Regions with high variability are also significantly impacted: western boundary currents, southern Indian Ocean, Antarctic Circumpolar Current 
(ACC) and Arabian Sea. There is no significant difference in the Pacific Ocean at that depth for this date.

Figure 10 shows the RMS of the salinity differences between Run-Ref and Run-NoArgo. Similar results are obtained for salinity and temperature. In the 0-300 m layer, the impact of the assimilation of Argo salinity profiles is spread over all of the world's oceans. The RMS of the salinity difference between OSEs reaches 0.1 psu in most of the oceans. Tropical oceans and western boundary current regions are the most affected: RMS exceeds 0.2 psu in these areas. The tropical Atlantic is the most sensitive region. The Amazon outflow is extremely active and the sensitivity of the analyses to the assimilation of Argo profiles is clear to see.

It is also noticeable that the Labrador Sea, mainly along its shelf break, is very sensitive to Argo profile assimilation. The analyses for the "boundary" between the Indian Ocean and the Antarctic, where the subtropical front approaches the Agulhas Front, are also highly affected. The analysis of these different water masses is obviously very sensitive to Argo salinity and temperature profile assimilation.

In the 700-2000 m layer, the greatest impact is found in the North Atlantic. The RMS of the salinity differences reaches $0.1 \mathrm{psu}$ along the European coast, due to the ill-positioning of the Mediterranean outflow in the model forecasts, and is around $0.05 \mathrm{psu}$ elsewhere in the basin. As for temperature, high-variability regions are strongly affected by Argo profile assimilation: Arabian Sea, Agulhas Current region, South America west boundary region and southern Indian Ocean. Again, the Pacific Ocean is far less affected.

Figure 11 shows the spatial distribution of the mean and RMS of the salinity difference between Argo observations and the Run-Ref analysis which assimilates Argo observations together with satellite and other in situ observations. The RMS and mean statistics are calculated in $2^{\circ} \times 2^{\circ}$ boxes and in the 0-300 and 700-2000 $\mathrm{m}$ layers. This shows that the system performs best when all Argo floats are assimilated. Compared to Fig. 4a, b, c and d where no Argo data were assimilated, the misfit with in situ observation is considerably reduced. Results are similar for salinity and temperature. For salinity, Run-Ref will also be considered as our best salinity estimate of the real ocean and we will also further quantify the impact of Argo observations by comparing Run-Argo2 and Run-NoArgo analyzed salinity fields to Run-Ref ones.

Figure 12 shows the evolution of the daily salt content anomaly in different regions of the global ocean and for different layers. The salt content anomaly is calculated by subtracting the 3-year mean (2011-2013) salinity of the Run-Ref from the OSEs' analyzed salinity. Time series for the global ocean, North Atlantic $\left(20-60^{\circ} \mathrm{N}, 5-70^{\circ} \mathrm{W}\right)$, North Pacific $\left(20-60^{\circ} \mathrm{N}, 110^{\circ} \mathrm{W}-120^{\circ} \mathrm{E}\right)$ and Southern Ocean $\left(50-70^{\circ} \mathrm{S}\right.$, $\left.180^{\circ} \mathrm{W}-180^{\circ} \mathrm{E}\right)$ are plotted. The different OSEs are represented by different colors. Blue is for Run-Ref, light blue is for Run-Argo2 and black is for Run-NoArgo.

The global estimate of the salt anomaly (Fig. 12a) shows differences depending on whether it is calculated with Run-
Ref, Run-Argo2 or Run-NoArgo. This masks some larger differences in regional estimates. Even the salt anomaly estimate in the surface layers from 0 to $300 \mathrm{~m}$ shows a strong sensitivity to the assimilation of Argo profile data, especially in the Southern Ocean. At depths between 700 and $2000 \mathrm{~m}$, where Argo is nearly the only in situ observing system available, the impact on the estimated variability of the salt anomaly is significant compared to the natural variability, even on 1-year experiments. The results for the North Atlantic are the most heavily affected. The contribution of the $700-2000 \mathrm{~m}$ layer to the $0-2000 \mathrm{~m}$ layer salt anomaly is not negligible.

In most of the regions, salt content estimation differs depending on whether only half or the full Argo array is assimilated. The estimates obtained with half of the Argo array are, in most cases, closer to the estimate obtained with the full Argo array than the simulation without Argo, but the differences are still significant compared to the anomaly itself.

\subsection{Impact on forecast fields}

In this section, the impact of Argo data assimilation on shortterm forecasts $(<7$ days) is evaluated using the innovation (observation values minus model forecast values) statistics. OSEs forecast fields are compared with the Argo and other in situ observations. The statistics are computed over the last 6 months of the experiment.

\subsubsection{Temperature innovations}

Figure 13 shows the global average RMS of the temperature innovation from 0 to $2000 \mathrm{~m}$ for the last 6 months of the RunRef, Run-Argo2, Run-NoArgo and Free Run experiments.

For each experiment, the RMS is greatest at approximately $100 \mathrm{~m}$ and decreases with depth. The amplitude of the RMS temperature innovations below $1000 \mathrm{~m}$ is very low compared to the mixed layer depth values, but global variability at that depth is obviously also very low. The RMS of temperature innovation decreases with increasing quantity of Argo data assimilated. Atmospheric forcing and assimilation of SST and SLA may explain the good surface results for Run-Ref, RunArgo 2 and Run-NoArgo.

Figure 14a shows the temporal mean RMS temperature innovation profile of the previous 6-month time series from the surface down to $2000 \mathrm{~m}$. This is a standard procedure for characterizing the performance of a forecasting system and evaluating the impact of an observing system (Oke and Schiller, 2007; Vidard et al., 2007; Fujii et al., 2014; Lea et al., 2014; Guinehut et al., 2012). The maximum RMS is found at $100 \mathrm{~m}$ for the four experiments, but the RMS of the innovations ranges from $1.4{ }^{\circ} \mathrm{C}$ for Free Run to $0.9^{\circ} \mathrm{C}$ for Run-Ref. The RMS of temperature innovations is improved in the whole water column when Argo temperature profiles are assimilated. However, at depths greater than $1400 \mathrm{~m}$, the RMS for temperature innovation of the Free Run experiment 
Table 2. Temperature forecast skill improvement derived from the reduction of the RMS temperature innovations.

\begin{tabular}{lll}
\hline & Forecast skill improvement due to assimilation & Forecast skill improvement due to assimilation \\
\hline & of the first half of the Argo array & of the global Argo array \\
$0-2000 \mathrm{~m}$ & from 10 to $30 \%$ & from 15 to $50 \%$ \\
$0-300 \mathrm{~m}$ & from 10 to $15 \%$ & around $18 \%$ \\
$700-2000 \mathrm{~m}$ & from 10 to $30 \%$ & from 20 to $50 \%$
\end{tabular}

Table 3. Salinity forecast skill improvement derived from the reduction of the RMS salinity innovations.

\begin{tabular}{|c|c|c|}
\hline & Forecast skill improvement due to assimilation & Forecast skill improvement due to assimilation \\
\hline & of the first half of the Argo array & of the global Argo array \\
\hline $0-2000 \mathrm{~m}$ & from 20 to $40 \%$ & from 20 to $65 \%$ \\
\hline $0-300 \mathrm{~m}$ & around $20 \%$ & from 20 to $30 \%$ \\
\hline $700-2000 \mathrm{~m}$ & from 20 to $40 \%$ & from 30 to $65 \%$ \\
\hline
\end{tabular}

is lower than the RMS for temperature innovation of the RunNoArgo. This result shows the importance of Argo $T$ and $S$ profile assimilation for ensuring a good projection at depth of the SLA and SST innovation by the multivariate data assimilation system.

On Figure 14b, each RMS temperature innovation profile shown in Fig. 14a is normalized with the Run-Ref RMS innovation profile, which represents our best forecast, shown in grey in Fig. 14a and b. We can then quantify the degradation of system performance in terms of temperature RMS error forecast due to the decrease of the number of Argo profiles assimilated. From those normalized profiles, we deduce an estimation of the percentage of degradation of the system performance for different depth ranges, summarized in Table 2. Coarsely, improvements range from $10 \%$ in the 0 $300 \mathrm{~m}$ layer to $50 \%$ in the $700-2000 \mathrm{~m}$ layer. Assimilation of the first half of the Argo array improves the performance of the system by $15 \%$ from the surface to $300 \mathrm{~m}$ depth and from 15 to $30 \%$ in the $700-2000 \mathrm{~m}$ layer. The assimilation of the second part of the array improves the performance of the system by around $5 \%$ in the $0-300 \mathrm{~m}$ depth and by $10-20 \%$ in the 700-2000 $\mathrm{m}$ layer.

\subsubsection{Salinity innovation}

The same calculations are performed for salinity as for temperature. Figure 15 is a time series of the RMS of salinity profile innovations for the last 6 months of experiments. RunRef, Run-Argo2, Run-NoArgo and Free Run time series are represented here.

The RMS error is greatest at the surface and decreases with depth. From 0 to $2000 \mathrm{~m}$ the more salinity data are assimilated the closer to the observation the forecasts become. There is no significant increase of the innovation RMS during the 6-month experiment for Run-Ref and Run-Argo2 as there is in Run-NoArgo and Free Run. This increase becomes visible at around $300 \mathrm{~m}$. This result demonstrates the importance of Argo observations for constraining salinity in the PSY3 system. Figure 16a shows the global mean absolute and normalized profiles of the RMS of salinity innovations for the different experiments. In the 0-300 $\mathrm{m}$ layer, the RMS innovation improvement depends on the quantity of Argo data assimilated by the system. Figure 16b shows that the RMS innovation is reduced by $20 \%$ when the first half of Argo profiles is assimilated, compared to the RMS innovation without Argo data assimilated. The assimilation of the second half of the Argo data set reduces it by a further $5-10 \%$ relative to the best scores (Run-Ref in blue). In the 700-2000 m layer, the increase of the quantity of Argo data assimilated, together with SLA and SST, induces a decrease of the RMS misfit in salinity.

This again shows the need for a good coverage of in situ profiles to estimate a coherent $T$ and $S$ 3-D correction from data assimilation of SLA and SST. The improvement corresponding to the assimilation of $50 \%$ of the Argo array is from 20 to $40 \%$ in that layer, compared to Run-NoArgo. Assimilation of the second half of the Argo array reduces the RMS innovation by a further 10-25\% compared to the best results. These values are recapitulated in Table 3 .

\subsubsection{SST and SSH innovations}

To validate the assimilation process, we briefly look at the impact of the assimilation of temperature and salinity profiles on other model-forecasted variables. It allows checking the physical consistency of the increment with the model physics. An "unbalanced" increment will destroy model equilibriums.

The global RMS of the SST innovations does not differ in the simulations with and without Argo data assimilated. The mean RMS is close to $0.6^{\circ} \mathrm{C}$ over the last 6 months of the OSE experiments. The temperature in the surface layers of the PSY3 system is highly constrained by the assimilation of the Reynolds SST maps. This can be seen in the RMS in- 
novation profiles of in situ observations that are small and close to the surface even when no Argo observations are assimilated. It also shows that globally the surface temperature observations from SST and in situ observations are coherent.

The global RMS of the SSH innovations also does not differ significantly between the OSEs with and without assimilated Argo $T$ and $S$ profiles. They stay close to $7 \mathrm{~cm}$ in RMS. Although the assimilation of in situ observations leads to a better 3-D estimation of the $T$ and $S$ fields, it does not change globally the fit to the SSH. Regional incoherencies were identified in our system between the information on dynamical height brought by the altimetry referenced to a MDT and the in situ data set. The projection of the altimetry data at depth on $T$ and $S$ fields is changed when Argo data are assimilated. Further investigation is required to study the complementarity of the in situ and SLA data set in our system and possible incoherencies.

\section{Conclusion}

Observing system experiments were carried out with the Mercator Ocean $0.25^{\circ}$ global ocean system to quantify the impact of Argo data assimilation. We considered the effect of Argo data assimilation on the 0-2000 m layer, focusing on the $0-300 \mathrm{~m}$ layer and on the 700-2000 m layer, where Argo observations are almost the only in situ observing system. The different OSEs cover the year 2012.

The quality of the 3-D temperature and salinity analyses without Argo observations was first assessed. This highlighted the system's weaknesses when only SST, SLA and non-Argo in situ data are assimilated. Without Argo data assimilated, large errors are found in the western boundary currents, Antarctic Circumpolar Current, the Mediterranean and Red Sea outflows and in the tropics.

The effect of Argo data assimilation was then assessed through the comparison of the analyzed temperature and salinity fields over the last 6 months from the different experiments. The comparison of the Run-Ref and Run-NoArgo experiments highlights the high sensitivity of the analyses to Argo data assimilation. The 6-month RMS differences of daily fields between these experiments easily reach $1{ }^{\circ} \mathrm{C}$ and $0.1 \mathrm{psu}$ at $100 \mathrm{~m}$ and $0.3^{\circ} \mathrm{C}$ and $0.05 \mathrm{psu}$ at $1000 \mathrm{~m}$. The location of the main differences is strongly correlated to regions with high variability, both at the surface and at depth. Strong effects are also noted in the Red Sea, and in the Amazon and Mediterranean outflow regions. Regions sensitive to Argo data assimilation coincide well with the regions where there is a large difference between analyzed fields without Argo observations and in situ observations. The density of the Argo data assimilated also has a considerable impact on the estimated evolution of heat content and mean salinity anomalies in both the surface layer from 0 to $300 \mathrm{~m}$ and the 700-2000 $\mathrm{m}$ layer, the latter being mainly unobserved without Argo observations. Finally, we evaluate the impact of the
Argo profile assimilation in the PSY3 forecasting system by computing the RMS differences between in situ observations and forecast fields for the different OSEs. Through Argo assimilation, the differences between observation and forecast fields are reduced by about $20 \%$ in the $0-300 \mathrm{~m}$ layer and by between 20 and $65 \%$ in the $700-2000 \mathrm{~m}$ layer. Results at depth show the importance of the global spatial coverage of Argo assimilation for constraining the temperature and salinity 3-D correction, deduced from data assimilation of SLA and SST, for more realistic results.

We show that the changes seen in the analyzed PSY3 temperature and salinity fields when Argo is assimilated correspond to an improvement of the analysis and forecast fields in terms of innovation and residuals to in situ observations. This shows the ability of the data assimilation system to take advantage of the Argo observations. The progressive improvement of the system's forecasting skills from assimilation of half of the Argo array to the full Argo array also indicates that all observations are needed to constrain our system. These results highlight the major importance of Argo data assimilation for operational oceanography. A decrease in the existing coverage of the Argo array would lead to a degradation of the PSY3 global ocean analysis and forecasts.

Finally, it is important to bear in mind that results from OSEs depend on the modeling and data assimilation system used. Our study takes place in the context of short-term realtime ocean analyses and forecasts. The conclusions could not be generalized to other ocean reanalyses without further investigation. The impact of Argo data assimilation on the other model variables also has to be further investigated. Here we focus on the impact of Argo observations on the reconstruction of 3-D temperature and salinity fields. Furthermore, we did not keep any in situ independent data sets as we stayed close to the real-time PSY3 system. General statements about observing systems should only be made with caution unless consistent results based on several systems are obtained. This is the approach promoted by the GODAE OceanView OSE/OSSE (observing system experiment/observing system simulation experiment) task team.

Acknowledgements. The research leading to these results received funding from the European FP7 program under the E-AIMS project. The authors would like to thank Jean-Michel Lellouche and Olivier Le Galloudec for providing support on the use of the operational system, Charly Régnier for providing the diagnostic tools and Gilles Garric and Yann Drillet for comments on an earlier version of the manuscript.

The altimeter products were produced by Ssalto/Duacs and distributed by Aviso with support from CNES (http://www.aviso. altimetry.fr/).

MDT_CNES-CLS09 was produced by the CLS Space Oceanography Division and distributed by Aviso, with support from CNES (http://www.aviso.altimetry.fr/).

Edited by: P. Chapman 


\section{References}

Balmaseda, M., Anderson, D., and Vidard, A.: Impact of Argo on analyses of the global ocean, Geophys. Res. Lett., 34, L16605, doi:10.1029/2007GL030452, 2007.

Bell, M. J., Le Traon, P.-Y., Smith, N., Lefebvre, M., and WilmerBecker, K.: The Global Ocean Data Assimilation Experiment (GODAE), Oceanography, 22, 14-21, 2009.

Bloom, S. C., Takacs, L. L., da Silva, A. M., and Ledvina, D.: Data assimilation using Incremental Analysis Updates, Monthly Weather Review, 124, 1256-1271, 1996.

Cabanes, C., Grouazel, A., von Schuckmann, K., Hamon, M., Turpin, V., Coatanoan, C., Paris, F., Guinehut, S., Boone, C., Ferry, N., de Boyer Montégut, C., Carval, T., Reverdin, G., Pouliquen, S., and Le Traon, P.-Y.: The CORA dataset: validation and diagnostics of in-situ ocean temperature and salinity measurements, Ocean Sci., 9, 1-18, doi:10.5194/os-9-1-2013, 2013.

Cazenave, A. and Llovel, W.: Contemporary sea level rise, Annual Review of Marine Science, 2, 145-173, 2010.

Dibarboure, G., Pujol, M.-I., Briol, F., Le Traon, P.-Y., Larnicol, G., Picot, N., Mertz, F., and Ablain, M.: Jason-2 in DUACS: first tandem results and impact on processing and products, Marine Geodesy, Jason-2 Special Issue, 34, 214-241, doi:10.1080/01490419.2011.584826, 2011.

Domingues, C. M., Church, J. A., White, N. J., Glecker, P. J., Wijffels, S. E., Barker, P. M., and Dunn, J. R.: Improved estimates of upper-ocean warming and multi-decadal sea-level rise, Nature, 453, 1090-1094, doi:10.1038/nature07080, 2008.

Fujii, Y., Cummings, J., Xue, Y., Schiller, A., Lee, T., Balmaseda, A. M., Remy, E., Masuda, S., Alves, O., Brassington, G., Cornuelle, B., Martin, M. J., Oke, P. R., Smith, G., and Yang, X.: Evaluation of the Tropical Pacific Observing System from the Ocean Data Assimilation Perspective, TPOS2020 Workshop, 27 January 2014, Scripps Inst. Of Oceanogr., USA, 2014.

Guinehut, S., Dhomps, A.-L., Larnicol, G., and Le Traon, P.Y.: High resolution 3-D temperature and salinity fields derived from in situ and satellite observations, Ocean Sci., 8, 845-857, doi:10.5194/os-8-845-2012, 2012.

Hansen, J., Nazarenko, L., Ruedy, R., Sato, M., Willis, J., Del Genio, A., Koch, D., Lacis, A., Lo, K., Menon, S., Novakov, T., Perlwitz, J., Russell, G., Schmidt, G. A., and Taunsnev, N.: Earth's energy imbalance: Confirmation and implications, Science, 308, 1431-1435, doi:10.1126/science.1110252, 2005.

Large, W. G. and Yeager, S. G.: The Global Climatology of an interannually varying air-sea flux data set, Clim. Dynam., 33, 341364, doi:10.1007/s00382-008-0441-3, 2009.

Lea, D. J., Martin, M. J., and Oke, P. R.: Demonstrating the complementarity of observations in an operational ocean forecasting system, Q. J. Roy, Meteor. Soc., 140, 2037-2049, doi:10.1002/qj.2281, 2013.

Lellouche, J.-M., Le Galloudec, O., Drévillon, M., Régnier, C., Greiner, E., Garric, G., Ferry, N., Desportes, C., Testut, C.-E., Bricaud, C., Bourdallé-Badie, R., Tranchant, B., Benkiran, M., Drillet, Y., Daudin, A., and De Nicola, C.: Evaluation of global monitoring and forecasting systems at Mercator Océan, Ocean Sci., 9, 57-81, doi:10.5194/os-9-57-2013, 2013.

Levitus, S., Antonov, J., and Boyer, T.: Warming the world ocean, 1955-2003, Geophys. Res. Lett., 32, L02604, doi:10.1029/2004GL021592, 2005.
Lindstrom, E., Gunn, J., Fischer, A., McCurdy, A., and Glover, L. K.: A Framework for Ocean Observing. By the Task Team for an Integrated Framework for Sustained Ocean Observing, UNESCO 2012, IOC.INF-1284, doi:10.5270/OceanObs09FOO, 2012.

Madec, G. and the NEMO team: NEMO ocean engine. Note du Pôle de modélisation, Institut Pierre-Simon Laplace (IPSL), France, No. 27, ISSN No 1288-1619, 2008.

Oke, P. R. and Schiller, A.: Impact of Argo, SST, and altimeter data on an eddy-resolving ocean reanalysis, Geophys. Res. Lett., 34, L19601, doi:10.1029/2007GL031549, 2007.

Oke, P. R., Larnicol, G., Fujii, Y., Smith, G. C., Lea, D. J., Mourre, B., Guinehut, S., Remy, E., Balmaseda, M. A., Rykova, T., Surcel-Colan, D., Martin, M. J., Sellar, A. A., Mulet, S., and Turpin, V.: Assessing the impact of observations on ocean forecasts and reanalyses: Part 1: Global studies, Journal of Operational Oceanography, 8, sup1, s49-s62, doi:10.1080/1755876X.2015.1022067, 2015a.

Oke, P. R., Larnicol, G., Jones, E. M., Kourafalou, V., Sperrevik, A. K., Carse, F., Tanajura, C. A. S., Halliwell, G. R., Le Hénaff, M., and Atlas, R.: Assessing the impact of observations on ocean forecasts and reanalyses: Part 2: Regional applications, Journal of Operational Oceanography, 8, sup1, s63-s79, doi:10.1080/1755876X.2015.1022080, 2015b.

OOPC: Report of the Tropical Pacific Observing System 2020 Workshop (TPOS2020), White Paper - Vol.II, available at: http://www.iode.org/index.php?option=com_oe\&task= viewDocumentRecord\&docID=13163 (last access: July 2014), 2014.

Pham, D. T., Verron, J., and Roubaud, M. C.: A singular evolutive extended Kalman filter for data assimilation in oceanography, J. Marine Syst., 16, 323-340, 1998.

Reynolds, R. W., Smith, T. M., Liu, C., Chelton, D. B., Casey, K. S., and Schlax, M. G.: Daily high-resolution blended analyses for sea surface temperature, J. Climate, 20, 5473-5496, 2007.

Rio, M. H., Guinehut, S., and Larnicol, G.: New CNES-CLS09 global mean dynamic topography computed from the combination of GRACE data, altimetry and in-situ measurements, J. Geophys. Res., 116, C07018, doi:10.1029/2010JC006505, 2011.

Tranchant, B., Testut, C.-E., Renault, L., Ferry, N., Birol, F., and Brasseur, P.: Expected impact of the future SMOS and Aquarius Ocean surface salinity missions in the Mercator Ocean operational systems: New perspectives to monitor ocean circulation, Remote Sens. Environ., 112, 1476-1487, doi:10.1016/j.rse.2007.06.023, 2008.

Trenberth, K. E. and Fasullo, J. T.: The Ocean is warming, isn't it? Nature, 465, p. 304, 2010.

Vidard, A., Anderson, D. L. T., and Balmaseda, M.: Impact of Ocean Observation Systems on Ocean Analysis and Seasonal Forecasts. Mon. Weather Rev., 135, 409-429, doi:10.1175/MWR3310.1, 2007.

Von Schuckmann, K., Gaillard, F., and Le Traon, P.-Y.: Global hydrographic variability patterns during 2003-2008, J. Geophys Res.-Oceans, 114, 1-17, doi:10.1029/2008JC005237, 2009.

von Schuckmann, K. and Le Traon, P.-Y.: How well can we derive Global Ocean Indicators from Argo data?, Ocean Sci., 7, 783791, doi:10.5194/os-7-783-2011, 2011. 
Willis, J. K., Lymann, J. M., Johnson, G. C., and Gilson, J.: In-situ data biases and recent heat content variability, J. Atmos. Ocean. Tech., 26, 846-852, 2009.
Wong, A. P. S., Keeley, R., Carval, T., and the Argo Data Management Team: Argo quality control manual, Version 2.31. ar-um04-01, 33 pp., 2008. 